IZA DP No. 10148

Women's Enfranchisement and Children's Education:

The Long-Run Impact of the U.S. Suffrage Movement

Esra Kose

Elira Kuka

Na'ama Shenhav

August 2016 


\title{
Women's Enfranchisement and Children's Education: The Long-Run Impact of the U.S. Suffrage Movement
}

\author{
Esra Kose \\ University of California, Davis \\ Elira Kuka \\ Southern Methodist University \\ and IZA \\ Na'ama Shenhav \\ Dartmouth College
}

Discussion Paper No. 10148

August 2016

\author{
IZA \\ P.O. Box 7240 \\ 53072 Bonn \\ Germany
}

Phone: +49-228-3894-0

Fax: +49-228-3894-180

E-mail: iza@iza.org

Any opinions expressed here are those of the author(s) and not those of IZA. Research published in this series may include views on policy, but the institute itself takes no institutional policy positions. The IZA research network is committed to the IZA Guiding Principles of Research Integrity.

The Institute for the Study of Labor (IZA) in Bonn is a local and virtual international research center and a place of communication between science, politics and business. IZA is an independent nonprofit organization supported by Deutsche Post Foundation. The center is associated with the University of Bonn and offers a stimulating research environment through its international network, workshops and conferences, data service, project support, research visits and doctoral program. IZA engages in (i) original and internationally competitive research in all fields of labor economics, (ii) development of policy concepts, and (iii) dissemination of research results and concepts to the interested public.

IZA Discussion Papers often represent preliminary work and are circulated to encourage discussion. Citation of such a paper should account for its provisional character. A revised version may be available directly from the author. 


\section{ABSTRACT}

\section{Women's Enfranchisement and Children's Education: The Long-Run Impact of the U.S. Suffrage Movement}

While a growing literature has shown that empowering women leads to increased short-term investments in children, little is known about its long-term effects. We investigate the effect of women's political empowerment on children's human capital accumulation by exploiting plausibly exogenous variation in U.S. state and federal suffrage laws. We estimate that exposure to women's suffrage during childhood leads to large increases in educational attainment for children from economically disadvantaged backgrounds, in particular blacks and Southern whites. An investigation into the mechanisms behind these effects suggests that the educational gains are plausibly driven by the rise in public expenditures following suffrage.

JEL Classification: $\quad 121$, N32

Keywords: women empowerment, suffrage, education

Corresponding author:

Na'ama Shenhav

Department of Economics

Dartmouth College

6106 Rockefeller Hall

Hanover, NH 03755

USA

E-mail: naama.shenhav@dartmouth.edu

\footnotetext{
* We thank Doug Miller, Marianne Page, Hilary Hoynes, Scott Carrell, and Peter Lindert for many helpful conversations and support. We are also grateful for the input that we received from Marcella Alsan, Celeste Carruthers, Bill Collins, Andrew Goodman-Bacon, Jae Wook Jung, Paco Martorell, Chris Meissner, Giovanni Peri, Sarah Reber, Shu Shen, Marianne Wanamaker, and seminar participants at UC Davis and the University of Oklahoma. We benefited from data made publicly available by Daniel Aaronson and Bhashkar Mazumder; Daron Acemoglu, David Autor, and David Lyle; Claudia Goldin; Lawrence Kenny; and Adrianna Lleras-Muney. We are thankful to Shahar Sansani and David Card for their generosity with schooling quality data. Our work was supported by a generous grant from the All-UC History Group, as well as the National Academy of Education/Spencer Dissertation Fellowship. All errors are our own.
} 


\section{Introduction}

"II]f we are talking about global economic growth ... there is no path forward that does not include the empowerment of women."

- Hillary Clinton, 9/23/2014

Women's economic and political empowerment is at the forefront of the policy agenda as a growing literature in economics suggests that empowering women could lead to economic development and growth. Research in both developed and developing countries has shown that greater economic and political power in the hands of women leads to increased household expenditures and funding for social programs directed towards children. ${ }^{1}$ Together, these findings provide evidence of systematic differences in preferences for investments in children between men and women. Less understood is whether these interests are shared closely enough amongst women to enact change on an aggregate level. And despite the increasing evidence of the positive effects of women's empowerment on short-term investments in children, little is known about its long-term benefits on human capital, development, or growth.

In this paper we provide the first of such evidence for a broad expansion of political power by analyzing whether women's enfranchisement in the Unites States led to increased educational attainment for exposed cohorts. The series of U.S. suffrage laws has been hailed as a "turning point in our Nation's history" (Obama, 2010); representing the single largest expansion, and arguably the most substantial transformation, of the American electorate. Newly empowered women exercised their vote in large numbers, as demonstrated by a $40 \%$ increase in voting among the adult population in the years following women's enfranchisement. ${ }^{2}$ The lasting legacy of the suffrage movement is evident in the current political landscape, which features an increasing presence of women at all levels of government.

Importantly, the initial surge of women voters was not simply an expansion of the electorate; it ushered in a new era of policymaking. Responding to an expanded electorate which emphasized children's welfare as a top priority, lawmakers increasingly voted for liberal legislation and sharply expanded public spending programs. Prior work by Lott and Kenny (1999) and Miller (2008) establishes that expenditures on social and health spending

\footnotetext{
${ }^{1}$ Duflo (2012) provides a nice overview of empirical findings in this vein. Also, see Thomas (1990); Duflo (2003); Thomas (1993); Chattopadhyay and Duflo (2004); Clots-Figueras (2012); Lundberg et al. (1997); Carruthers and Wanamaker (2014); Aidt and Dallal (2008). For a theoretical approach, see Doepke and Tertilt (2009), which develops a model of the incentives for power-sharing with women, linking the increase in women's power to men's desire to increase educational attainment of their children.

${ }^{2}$ For the rise in voting in gubernatorial races, see Lott and Kenny (1999); presidential elections, see authors' calculations in Section 3.
} 
programs rose by $36 \%$ and $24 \%$, respectively, following the passage of the state laws. ${ }^{3}$ Other investigations credit suffrage with up to a 29 percent increase in education expenditures as well as the passage of public health initiatives, including the Maternal and Infancy Protection Act. ${ }^{4}$ We hypothesize that public expenditures targeted at education, health, and social capital are a primary channel for improvements in education. Yet to date there is little evidence that the passage of suffrage and the accompanying infusion of public resources left any lasting impacts on the well-being of children, the intended beneficiaries.

The uniquely decentralized process of female enfranchisement in the United States provides an ideal context for studying the impact of women's political empowerment. The majority of suffrage laws were passed by U.S. state legislatures between 1910 and 1920, and then mandated for the remaining states through a federal constitutional amendment. The quick succession of the laws in a short time period supports the comparison of outcomes across states while introducing substantial variation across cohorts within the state. In that sense, our study is well-positioned to provide evidence of a plausibly more broad-based and systemic empowerment to a literature that has previously been limited to expansions in female representation in local governments (Chattopadhyay and Duflo, 2004; Clots-Figueras, 2012; Ferreira and Gyourko, 2014).

Our empirical strategy exploits changes in voting laws across states and in exposure to the laws across cohorts, in a similar approach to the one successfully utilized in Lott and Kenny (1999) and Miller (2008). More specifically, we use a generalized differencein-difference strategy that compares cohorts that were not of schooling age at the passage of the laws (control children) to cohorts that were of schooling age or not yet born when suffrage was enacted (treated children). The key identification assumption is that the timing of the laws is not correlated with differential trends in educational attainments across states. Previous studies have shown their timing to be uncorrelated with a host of state policies, economic and political factors, and demographics (Lott and Kenny, 1999; Miller, 2008). We also rule out changes in the demographic composition of the state as a source of confounding variation. Moreover, we explicitly test this identification assumption by estimating event study specifications that allow suffrage laws to have a differential impact at each age of exposure to the laws. These specifications rule out the existence of differential pre-trends

\footnotetext{
${ }^{3} \mathrm{~A}$ related literature investigates the effects of black (dis)enfranchisement through the (enactment) removal of poll taxes and literacy tests, and finds that the ability to vote leads to greater expenditures directed towards those communities, higher teacher-pupil ratios and enrollment (Cascio and Washington, 2013; Naidu, 2012).

${ }^{4}$ Passed in 1921, The Promotion of the Welfare and Hygiene of Maternity and Infancy Act, abbreviated as the Maternal and Infancy Protection Act or more commonly as the "Shepphard-Towner" Act, provided federal matching grants to states for the implementation of public health programs directed towards improving mother and infant health (Moehling and Thomasson, 2012).
} 
between our treatment and control groups.

To estimate the effects of women's enfranchisement on human capital, we utilize information on the state of birth and educational attainment of individuals from the 1880 to 1930 birth cohorts in the 1940, 1950, and 1960 decennial censuses. We supplement this data with information on the literacy of individuals from the same cohorts in the 1920 and 1930 censuses.

We find that suffrage had a large positive impact on the education of children concentrated among those from economically disadvantaged backgrounds. In particular, we find that full exposure to suffrage between the ages of 0 and 15 leads to an additional year of education for black children, who have an average of 5.2 years of education in the pre-treatment period, as well as for white children from the South, who have 8.0 years of education in the pre-treatment period. We show that the effect of suffrage is increasing with disadvantage, and in line with that result, find small effects of suffrage on the education of whites from outside the South. We also find that the effects on education are present at primary-level education, the mean schooling of the affected groups, which indicates that suffrage led to catch-up in large part by affecting the decision of children on the margin of leaving primary school.

We expand upon these results by examining the effects of suffrage on other measures of human capital accumulation and on labor market outcomes. We show that the effects on years of education are mirrored in an event study of literacy attainment, although less precisely estimated. Further, we find that white children that experienced improvements in education following suffrage also benefited from a higher income as adults.

We explore multiple channels that may explain this pattern of results. The totality of the evidence suggests that the results are driven by the rise in health and educational expenditures following suffrage, rather than by bargaining or modeling effects. The heterogenous impacts across regions and races are consistent with a model of diminishing returns to investment, in which the largest impacts are seen among those with the fewest initial resources. We also find suggestive evidence that improvements in health and education quality in the South may have been larger than in other areas, which may have contributed to the larger impacts in that region. Although we cannot isolate the specific mechanisms responsible for the gains, the magnitude of the effects suggests that our findings are unlikely to be explained purely by health improvements (Bhalotra and Venkataramani, 2011, e.g.), but could feasibly be driven by changes in schooling investments (Card and Krueger, 1992; Jackson et al., 2015). Therefore, we deduce that a combination of these channels contributed to the gains in education.

We bolster the credibility of the estimates in a variety of ways. First, the effects of 
suffrage are similar among states that did not voluntarily adopt the laws, eliminating the possibility of endogenous law passage as a potential source of bias. The point estimates as well as the event study patterns are similar across both groups of states. Second, we stratify our estimation by migration status to investigate the role of endogenous migration. We show that our results are present only among individuals that did not migrate, and we find attenuation consistent with measurement error among the migrants. Finally, we show our results are insensitive to a variety of state-level controls, as well as to restricting the analysis to one census year at a time. ${ }^{5}$

Our results contribute to the growing literature in economics that has shown that women have different preferences than men regarding household and community expenditures and investments in children. Research in developing countries has shown that income and assets in the hands of women lead to improvements in child health and to an increased share of household expenditures on housing and health (Thomas, 1990; Duflo, 2003; Thomas, 1993; Lundberg et al., 1997). Moreover, increasing women's political power has been associated with greater investment in public goods preferred by women, improved infant health, and increased primary educational attainment for cohorts affected by this type of political change (Aidt and Dallal, 2008; Chattopadhyay and Duflo, 2004; Clots-Figueras, 2012). ${ }^{6}$ These studies are limited to short-term effects, though, and often study limited changes in political representation which may not be generalizable to other policies. Our findings contribute the first long-term estimates of a broad-based expansion of women's political power.

Additionally, our findings align well with an increasing number of papers that find that public health, social, and education programs - those expanded under suffrage - benefit populations with the most need (Almond et al., 2011; Hoynes et al., 2011; Currie and Gruber, 1996; Bitler et al., 2014). Finally, our estimates add an additional source of educational growth to explain the rapid rise in attainment during the early $20^{\text {th }}$ century, a significant portion of which remains unexplained. ${ }^{7}$ We show that suffrage contributed to significant growth in education levels, accounting for $24 \%$ of the 4.2 years growth in educational attainment among Southern-born individuals in the sample.

\footnotetext{
${ }^{5}$ Goldin (1998) shows that the measure of educational attainment in the 1940 census is likely tainted by the rapid growth in high school attainment at the time of collection, implying that the data should be used with caution. Our results are invariant to the exclusion of the 1940 census.

${ }^{6}$ While this pattern holds in many cases, the election of female representatives does not always lead to altered spending; see e.g. Ferreira and Gyourko (2014).

${ }^{7} \mathrm{~A}$ large literature explores factors such as the institution of child labor and compulsory schooling laws, improved transportation options, philanthropic educational ventures, economic growth, and increasing economic self-sufficiency of blacks. See Goldin and Katz (2010) for an overview; Lleras-Muney (2002); Goldin and Katz (2003) for child labor and compulsory schooling laws; Aaronson and Mazumder (2011) for philanthropy in the South; and Collins and Margo (2006) for a detailed analysis of the evolution of the racial gap in schooling.
} 
The remainder of the paper continues as follows. We present the expected effects of suffrage and prior literature in Section 2. In Section 3 we provide institutional background on the passage of suffrage laws. Section 4 describes our data sources, followed by an overview of our empirical strategy in Section 5. We present our results in Section 6, robustness checks in Section 7 and conclude in Section 8.

\section{Expected Effects of Suffrage and Prior Literature}

Although women had gained some economic rights prior to the passage of suffrage (Baker, 1984; Doepke and Tertilt, 2009), enfranchisement was an important landmark for their empowerment. The ability to vote gave women influence over the direction of policymaking in two ways. First, enfranchisement provided women with access to direct democracy. Prior to suffrage, women could only marginally affect the election of representatives by influencing a male proxy, such as their husband. The ability to cast their own vote allowed women to have a voice in local policies and elect representation closer to their preferences. In aggregate, by nearly doubling the size of the electorate, suffrage shifted the interests of the median voter. Theory suggests that such a shift would be reflected in differential legislative representation following suffrage. Lott and Kenny (1999) show that this is indeed the case; liberal voting increased in both houses of Congress following suffrage.

A shared set of policy interests provides a second channel of influence for women. In the early years of suffrage in particular women's lobbies effectively created the perception of close political alignment among its members (Moehling and Thomasson, 2012; Lemons, 1973). In the case of the Virginia gubernatorial election in 1920, a former anti-suffragist was handily defeated due to organized opposition from the League of Women Voters; who instead endorsed the opposing candidate for his support of progressive legislation, including improved roads to allow rural children to attend school (Walker et al., 2003). Examples such as these may have led politicians concerned about retribution at the polls, on the margin, to choose to push forward legislation favored by women. This is also consistent with models of distributive politics which suggest that politicians will respond to the enfranchisement of a distinct and recognizable group of constituents through the distribution of resources towards the interests of the group (see, e.g. Cascio and Washington (2013); Dixit and Londregan (1996)).

Each of these political mechanisms supports a shift towards greater legislative efforts targeting children's welfare, a top policy priority among women of the suffrage movement. Although the movement was largely divided along racial lines, both white and black women saw suffrage as a vehicle for change (Wheeler, 1995; Green, 1997). For black women, sources 
suggest that suffrage was viewed as an opportunity to "help uplift the standard of their race through the franchise" (Wheeler, 1995), while white women hoped to use a newfound political power to address local concerns which "could not be solved by club actions alone" (Green, 1997). Moreover, women's organizations in the early 20th century lobbied for the passage of children's codes to regulate child work, guardianship, and mandatory school attendance (Lemons, 1973). The passage of the Maternal and Infancy Protection Act of 1921 and other public hygiene measures targeting child health have also largely been attributed to efforts of women's rights organization and the female-led Children's Bureau (Lemons, 1973).

Empirical analyses of the effects of suffrage have uncovered large effects of women's suffrage laws on public spending, on social and health programs in particular. Lott and Kenny (1999) find that suffrage led to a nationwide transformation of the government, including a $13.5 \%$ increase in state government expenditures and more liberal representation in Congress after the passage of suffrage. Extending these results, Miller (2008) estimates a 36\% increase in municipal expenditures towards charities and hospitals and a $24 \%$ increase in state spending on social programs. Both papers find that the increases in spending were sharp and followed immediately after the passage of the laws (Lott and Kenny, 1999; Miller, 2008), although the duration of the health spending increases has been debated (Moehling and Thomasson, 2012). Miller's analysis also finds that suffrage reduced child mortality by as much as $15 \%$, which he attributes to public sanitation projects funded after suffrage. Finally, Carruthers and Wanamaker (2014) link voting behavior post-suffrage to higher local spending on education for both white and black schools in three Southern states, with larger increases accruing to the white schools than to the black schools. ${ }^{8,9}$

Evidence from other interventions during this time period suggests that the effect of these expansions in government health and education programs could have had a significant impact on affected children. Bleakley (2007) finds that a hookworm eradication scheme generated large increases in school attendance and literacy and long term effects on income, although no statistically significant impact on attainment. ${ }^{10}$ Moreover, Aaronson and Mazumder (2011) find that a similarly-timed school-building program in the South (the "Rosenwald Initiative")

\footnotetext{
${ }^{8}$ The analysis in Carruthers and Wanamaker (2014) takes advantage of a unique dataset of local school spending by county and race in Alabama, Georgia, and South Carolina to overcome the limitation of prior studies of suffrage, which found null results of suffrage on state education spending. The estimated increases in education spending are positive in the first years following suffrage, and increase in magnitude over time.

${ }^{9}$ Since white schools experienced larger spending increases than black schools, Carruthers and Wanamaker (2014) predict that suffrage will lead to an increase in the educational gap between white and black children. However, this is not necessarily the case if the returns to educational spending are larger for blacks relative to whites.

${ }^{10}$ Given the coincidental timing of the hookworm eradication scheme, one may be concerned about confounding variation. However, there is no correlation between the pre-treatment hookworm infection and the year of suffrage; all of the treated states adopted suffrage in the same year.
} 
had significant effects on school attendance, literacy, years of schooling, cognitive test scores, and northern migration for blacks. ${ }^{11}$ In a follow-up study, Carruthers and Wanamaker (2013) clarify that the philanthropic funds actually benefited expenditures towards white and black schools, although white children did not show the same educational gains. Overall, these studies offer a large scope for improvements to human capital through targeted public programs, in particular from health and education spending.

Nonetheless, it remains ambiguous which populations, if any, would have benefited from such expansions. Importantly, although suffrage gave voting rights to women de jure, in practice black men and women were disenfranchised until the 1960s through literacy tests and poll taxes (Cascio and Washington, 2013; Naidu, 2012). Therefore, the consequences of suffrage rely on the magnitude of the shifts in the preferences of the median voter resulting from the introduction of white women to the electorate. This leaves open three possibilities for children's education, depending on the level of altruism of white women. First, if white women are completely self-interested and vote for representatives that would only approve funding that directly impacts their children, then we would expect no impacts outside that community. Second, suppose that white women are self-interested, but internalize the externality of negative outcomes, such as poor health, accruing to other children. In that case, we may expect an increase in resources targeted towards programs that benefit the population generally and which would indirectly improve the outcomes of white children (such as sanitation), and additional resources for goods that directly impact welfare of white children (such as local schooling). Finally, if white women are somewhat altruistic, then we expect that the median voter will influence representatives to increase resources for many public programs (public goods as well as school expenditures), though disproportionately for white children. This would also be consistent with a Tiebout-type model in which white women increase public provisions for the black community in order to attract black families and labor (Carruthers and Wanamaker, 2014).

Based on the previous literature, which finds impacts on resources for both whites and blacks, we leave open the possibility of impacts on all populations, and explore these potential mechanisms further in Section 6.4.

\footnotetext{
${ }^{11}$ From 1914-1931, approximately 5000 schools were constructed due to the enactment of Rosenwald Initiative in the rural south.
} 


\section{State-Level Passage of Women's Suffrage}

The passage of women's suffrage by states was an important first victory after a decadeslong struggle for the women's rights movement. ${ }^{12}$ According to one historian, "while some women had struggled to win the franchise since before the Civil War, not until the first decade of the twentieth century did it become a major issue to millions of women...New leaders, new tactics, new ideas, and new interest accounted for these leaps" (Lemons, 1973). In this section, we discuss the timeline of the passage of suffrage and explore the potential explanations for the timing of its spread.

We illustrate the sequence of the laws across states in Figure 1 using data from Lott and Kenny (1999) and Miller (2008). The first states to grant the vote to women were Wyoming, Utah, Colorado, and Idaho in 1869, 1870, 1893, and 1896, respectively. This group of "early adopter" states is noted for the distinctive environment in which they were passed. Located geographically in a cluster in the "Wild West", many political writings have discussed the favorable demographic and political conditions for suffrage (see Braun and Kvasnicka (2013) and references within). Among them are the notion of "frontier egalitarianism"; the need for greater equality of sexes to compensate for the harsh conditions of the West; a less stringent amendment process; and a relatively low political "cost" of suffrage to men due to the low number of women in the West (Braun and Kvasnicka, 2013; Engerman and Sokolof, 2005).

Almost fifteen years passed before the next state, Washington, adopted suffrage in 1910. Over the next ten years, a number of states passed suffrage laws in each year, which culminated in the 1920 passage of the Nineteenth Amendment, a federal mandate for women's voting rights. The Amendment obligated all states to enact suffrage, despite the fact that support of the Amendment was not unanimous. Three-fourths, or 36 of the 48 states, ratified the amendment prior to its passage. ${ }^{13}$ The remaining 12 states that did not voluntarily adopt the amendment provide us with a strong test of our empirical strategy, ${ }^{14}$ and we check for differential effects across the two groups of states in Section 7.

Although historical election data do not record voter turnout by gender, the aggregate voting patterns following the passage of suffrage provide strong visual evidence of a "first stage" effect of the policy. In Figure 2 we present an event study of the log of voter turnout relative to the population over 21 for presidential elections, ${ }^{15}$ centered around the passage of

\footnotetext{
${ }^{12}$ The Seneca Falls Convention, the first large-scale organizing meeting for women's rights, took place in 1848.

${ }^{13}$ The remaining states ratified the Amendment over the next sixty years. Mississippi was the final state to ratify the amendment in 1984 .

${ }^{14}$ Figure 1 also differentiates between these groups of states.

${ }^{15}$ We focus on presidential elections because turnout in presidential elections is higher than in other elections, and thus provides a more reliable measure of turnout (Cascio and Washington, 2013). Lott and
} 
suffrage in the state. ${ }^{16,17}$ Controlling for year-of-election fixed effects, state fixed effects, and state trends, we estimate that the turnout rate increased by 35 log points, or 41 percent, following suffrage. These estimates confirm that suffrage had a meaningful impact on the landscape of voting in the United States, and potentially also in the preferences of the median voter.

Our empirical strategy relies upon the idiosyncratic nature of the timing of suffrage laws. The discrete nature of the laws allows us to absorb smooth changes in potential confounding variables in the econometric specification, implying that confounding variation must be a departure from trends over time. Prior studies in this literature have explored this variation in detail and find few significant correlates of the laws. Dahlin et al. (2005) and Braun and Kvasnicka (2013) identify just two variables among many social, political, and cultural characteristic tested that are predictive of the passing of suffrage, the percent of women in non-agricultural occupations and the percent of women in the state. Miller (2008) performs a number of additional tests which verify that the laws were not correlated with any other progressive legislation during the period including regulations governing alimony and divorce, mother's pension, women's maximum hours, women's minimum wages, prohibition, worker's compensation, child labor, and compulsory schooling and were not correlated with the state literacy rate or manufacturing wages. We replicate his analysis, and additionally show that suffrage was not correlated with increases in compulsory schooling or child labor education requirements. ${ }^{18}$ These results serve to reassure us that the timing of suffrage laws was not correlated with the enactment of other confounding policies.

We also test whether there were discrete changes in any of a host of demographic and economic variables following suffrage, using a state-year panel spanning from 1915 to 1930 compiled by Lleras-Muney (2002). ${ }^{19}$ In order to be able to analyze changes in state conditions following suffrage, we restrict the sample to those states that passed suffrage in or after 1917, such that we have at least one observation prior to the passage of the law. In Panel A of Table 1 , we report the coefficients obtained from a regression of the listed state characteristic on a dummy for the post-suffrage period. We find borderline significant declines in farm value

Kenny (1999) perform a similar analysis using gubernatorial data and find a $48 \%$ increase in turnout following suffrage.

${ }^{16}$ In particular, we regress $\ln \left(\frac{\text { Total Turnout }_{s t}}{\text { Population } 21+_{s t}}\right)$ for state $s$ in year $t$ on a set of event time dummies centered around the year of suffrage, state fixed effects, state time trends, region by year fixed effects, and state-level controls. All coefficients are measured relative to $t \leq-9$, the omitted category.

${ }^{17}$ Voter turnout data are obtained from Electoral Data for Counties in the United States provided by ICPSR, see http://www.icpsr.umich.edu/icpsrweb/ICPSR/studies/8611. Population over age 21 is estimated using decennial census data (Ruggles et al., 2010) and interpolation between censuses.

${ }^{18}$ See Tables OA.1, OA.2 and OA.3 as well as Figure OA.1 in the Online Appendix.

${ }^{19}$ See Section 4 for more details regarding the data. Prior to 1915 the data are only available decennially, and therefore cannot be used to test for discrete changes following the passage of suffrage. 
and significant increases in manufacturing employment following suffrage. In Panels B and C, we further restrict the sample of states to those that passed suffrage between 1918 and 1920 in order to have a longer pre-period and to be able to additionally test for a break in a linear trend following suffrage. Here, only one variable, farm value is individually statistically significant, and no systematic pattern that emerges from the results. Overall, these results suggest that economic conditions and state demographics were not changing substantially with suffrage, and expect that the coinciding decline in farm value would at most bias us against finding an effect on education. ${ }^{20}$

We also wish to address the regional clustering of the passage of the laws in Figure 1, which may be problematic for our design if education outcomes are also spatially correlated. In Appendix Figure A.1, we plot the mean educational attainment by birth cohort for each of four Census-defined regions. ${ }^{21}$ Across all cohorts, the West leads in educational attainment, followed by the Midwest, the Northeast, and the South, which has far lower average educational levels than the other regions. ${ }^{22}$ This figure is the motivation for the use of a specification which abstracts from these regional comparisons. In particular, we incorporate a region by birth cohort fixed effect in our empirical specification, imposing comparisons within regional cohorts. We do so as a cautionary step despite the previous evidence that the timing of the laws was not correlated with adult literacy (Miller, 2008), which suggests that this control may not be necessary, and therefore consider our estimates to be a conservative estimate of the effects of suffrage.

\section{Data and Summary Statistics}

We analyze the effect of women's suffrage laws on children's educational outcomes using two pooled cross-sectional samples using data from the 1920 and 1930 censuses and the 1940, 1950 and 1960 U.S. decennial censuses. The bulk of our analysis focuses on impacts on educational attainment, which we observe in the latter sample; while the earlier samples allow us to also explore effects on literacy, which is not available after 1930. The data in each year are a $1 \%$ representative sample of the U.S. population and are publicly available

\footnotetext{
${ }^{20}$ We repeat this analysis for the years $1915-1925$ (keeping at most 5 post suffrage years), and all the coefficients are insignificant.

${ }^{21}$ See http://www2.census.gov/geo/pdfs/maps-data/maps/reference/us_regdiv.pdf for a map of these regions.

${ }^{22}$ Also evident from the figure is that there is a systematic drop in the years of reported schooling at years of birth ending in 0 or 5 . This is a reflection of age-heaping, or the excess number of individuals at round years of birth, which is seemingly associated with lower levels of education. As a result, we expect there to be some mis-assignment of treatment in the context of our analysis, which may cause some attenuation in our estimates.
} 
through the Integrated Public Use Microdata Series (IPUMS) (Ruggles et al., 2010). The Census collects detailed demographic and economic information at both the household and individual level. Relevant for our research design, the samples contain information on the year and state of birth, as well as the years of completed education for each individual (from 1940 on) $)^{23}$ and literacy (until 1930). State of birth serves as a proxy for childhood location and jointly with year of birth can be used to determine the extent to which each individual was "treated" by suffrage. We discuss this in further detail in Section 5.

We obtain the dates of women's enfranchisement for each state from Lott and Kenny (1999). Following the prior literature, we use the date of earliest suffrage, although in some states women were not granted full voting rights. ${ }^{24}$ The main motivation for doing so is the concern that the choice to extend partial or full suffrage rights may have been influenced by the uncertainty regarding the likelihood of federal enfranchisement, and that restricting to one group of states may therefore introduce selection into the analysis (Miller, 2008). In practice, the distinction has made little difference in prior work (Miller, 2008), as it does not in ours.

We conduct the following sample restrictions. First, we exclude individuals born in Alaska, the District of Columbia and Hawaii, which were not U.S. states by the time that the federal law was passed in 1920, and therefore not subject to the laws. ${ }^{25}$ Second, we drop individuals born in Colorado, Idaho, Utah and Wyoming, the states that enacted early suffrage laws (between 1869 and 1896), due to data limitations. Cohorts treated by the laws in these states are between forty and seventy years old at first observation in $1940,{ }^{26}$ and therefore their inclusions would raise issues of selective mortality and/or unbalanced panels. $^{27}$ After we exclude these early states, suffrage laws in the remaining states were enacted within a short time window, between 1910 and 1920.

Third, for the analysis of educational attainment we restrict the sample to individuals

\footnotetext{
${ }^{23}$ There is a slight discrepancy between the wording of the education question in the 1940 census and the 1950-1960 censuses. In the earlier census, the question asked for the highest grade completed, while in the later censuses, individuals are asked for the highest grade attended and separately whether the individual completed the highest grade attended. Our analysis makes use of the IPUMS "educ" variable, which harmonizes responses across censuses. We do not believe that the adjustment in the questionnaire text has an influence over our results.

${ }^{24}$ Presidential-only suffrage laws were passed in Illinois, Indiana, Iowa, Maine, Minnesota, Missouri, North Dakota, Ohio, Rhode Island, Tennessee, Vermont and Wisconsin. Arkansas and Texas, instead, passed primary-only laws (Miller, 2008).

${ }^{25}$ These states could serve as an interesting falsification test, but unfortunately compose too small of a sample to draw any meaningful conclusions from the results.

${ }^{26}$ Unfortunately, educational attainment was first collected in 1940 , so we can not observe these cohorts at a younger stage.

${ }^{27}$ We check the sensitivity of our results to these sample restrictions in Table OA.4. None of the sample restrictions are consequential for the results.
} 
that are at least 20 years old to allow time for individuals to have completed schooling. ${ }^{28}$ Further, the analysis sample for the literacy outcome is limited to individuals at least 15 years old in order to avoid bias from early schooling effects (Aaronson and Mazumder, 2011). Finally, we include only cohorts born between 1880 and 1930. With this restriction we obtain a panel that is balanced on cohort, although somewhat imbalanced on the age of treatment. Figure 3 visually depicts this variation across states by the year of suffrage. Highlighted in the figure is the substantial overlap across states in the "treatment age" of individuals in our sample, or the age of the individual when suffrage was passed in the state. This ensures that our estimates will not be biased due to variation in the sample composition across treatment ages.

After these restrictions we are left with a total of 1,555,475 observations for the analysis of educational attainment, of which 572,126, 227,541, and 755,808 are from the 1940, 1950, and 1960 Censuses respectively. ${ }^{29}$

Table 2 presents descriptive statistics for our sample, first for whites and blacks in the entire sample, and then for each of the four census regions separately. The first two columns illustrate the significant discrepancy in educational attainment across races. Relative to blacks, whites had substantially higher educational attainment, with a mean of 9.96 years compared with the black mean of 6.76 years. National means obscure important regional differences, however, such as those previewed in Appendix Figure A.1. For example, individuals from the South have much lower educational attainment than the rest of the country, 6.45 and 9.12 years for blacks and whites respectively, reflected in the lower literacy rates of the region. On the other hand, individuals from the West have higher levels of education, 10.38 and 11.02 years for blacks and whites respectively. Again, these regional differences highlight the need of within-region comparisons in the presence of regional variation in the timing of suffrage laws.

We augment the Census data with state-level variables that control for variation in demographic and economic composition and policies in the state, which may be confounded with suffrage. The variables include: percentage female; population; percentage white; percentage black; percentage illiterate; employment in manufacturing; total wages paid in manufacturing; total value of farm property; percentage urban population; and percentage foreign born.We source these measures from a combination of Lleras-Muney $(2002)^{30}$ and the ICPSR

\footnotetext{
${ }^{28} 75 \%$ of the sample completed at most 12 years of education, which corresponds to a school leaving age of 18 given that most white children began school by age 6 or 7 . For blacks, we would expect this cutoff to be even less relevant, given that many children completed less than 6 years of education, and began school around 8 years old. Our results are not sensitive to alternative age cutoffs, such as age 25. See Table OA.5.

${ }^{29}$ We have fewer observations from the 1950 Census because in that year the Census only collected information on years of education for one individual per household.

${ }^{30}$ These data are compiled from a number of sources; see http://www.econ.ucla.edu/alleras/
} 
data series "Historical, Demographic, Economic, and Social Data: The United States". ${ }^{31}$ The data from Lleras-Muney (2002) span the years 1915-1939 and have been utilized in many previous studies of this time period, such as Goldin and Katz (2010). The ICPSR data series, which harmonizes information from Census of Manufacturing and Census of Agriculture, allows us to extend this set of controls for the period from 1880-1914. ${ }^{32}$

Additionally, we include state-by-cohort measures of the intensity of relevant education policies. The most salient of these interventions is the introduction of state compulsory education and child labor laws, which were adopted in some form by all states by the early twentieth century (Acemoglu and Angrist, 2001; Goldin and Katz, 2003; Lleras-Muney, 2002; Stephens and Yang, 2014). The laws used the minimum schooling level to drop out, the minimum schooling level to obtain a work permit, the maximum school entry age, and the minimum school leaving age as levers in a set of policies that induced large gains in schooling (see Lleras-Muney (2002), for example). To capture the impact of these laws on schooling decisions we control for two measures of compulsory schooling for each cohort in the state, the compulsory attendance requirement and the child labor educational requirement. To do so, we aggregate annual data spanning from 1910 to 1944, combined from Goldin and Katz (2003) and Acemoglu and Angrist (2001), and assign the relevant laws following Stephens and Yang (2014). ${ }^{33,34}$ The Rosenwald Initiative, discussed previously, is another of such policies. We aggregate the county-level Rosenwald student exposure measure from Aaronson and Mazumder (2011) to generate a measure of the average reach of Rosenwald over the childhood of each individual. ${ }^{35}$

We take advantage of two additional data sources to investigate potential mechanisms through which the effect of suffrage on education might take place. To gain insight into the effects of suffrage on health, we digitized the Mortality Statistics files, which provide us with annual counts of deaths by state, age, race, and gender from 1900 to $1932 .{ }^{36}$ The

research/data.html for more detail.

${ }^{31}$ For the ICPSR data source, see: http://www.icpsr.umich.edu/icpsrweb/ICPSR/studies/2896.

${ }^{32}$ This data was reported every 10 years from 1860 forward; we linearly interpolate the intermediate years. Following Lleras-Muney (2002), all monetary values are adjusted for inflation using the Consumer Price Index, 1982-1984 as the base period.

${ }^{33}$ The measure of compulsory attendance, $C A$ is defined for each cohort $c$ born in state $s$ as follows: $C A_{c s}=\min \left\{\right.$ DropoutAge $_{c s}-$ EnrollmentAge $_{c s}$, YearsofSchoolNeededtoDropout $\left.t_{c s}\right\}$, where each of the components of $C A$ are determined by the prevailing laws in state $s$ in the year that $c$ turns 14. Child labor, $C L_{c s}$ is defined as: $C L_{c s}=\max \left\{W_{\text {orkPermitAge }}-\right.$ EnrollmentAge $_{c s}$, EducationforWorkPermit $\left._{c s}\right\}$. See Stephens and Yang (2014) for more detail. Note that since we only have these laws beginning in 1910, we assume that cohorts that turned 14 before 1910 (born between 1880-1896) were exposed to the 1910 laws. Our results are robust to other measures of the schooling laws used in the compulsory education literature.

${ }^{34}$ The data from Goldin and Katz (2003) and Acemoglu and Angrist (2001) span the years 1900-1939, and we use data from Acemoglu and Angrist (2001) for the years 1940-1944.

${ }^{35}$ For further detail about this data, visit http://www.jstor.org/stable/10.1086/662962.

${ }^{36}$ Prior to 1933, these Mortality Statistics are not available for all states. The "Death Registration Area", 
Statistics were originally published by the U.S. Bureau of the Census, but can be currently obtained from the Centers for Disease Control and Prevention. ${ }^{37}$ Additionally, we obtain several measures of state-level school quality from a compilation of two data sources. First, we make use of average pupil-to-teacher ratio and term length available from Card and Krueger (1992). ${ }^{38}$ To extend these data backwards, we use newly digitized information on these variables from 1900 to 1917, drawn from the annual Report of the Commissioner of Education published during this period. ${ }^{39}$ Combining these datasets, we obtain a state-year panel of the average pupil-to-teacher ratio and term length spanning from 1900 to $1930 .{ }^{40}$

\section{$5 \quad$ Empirical Strategy}

Our empirical strategy utilizes a generalized difference-in-difference approach, which compares the outcomes of cohorts born prior to the enfranchisement of women in the state, and hence less treated or untreated by the laws, to those born after the law's passage in the state, who were completely treated. Two identifying assumptions are needed to estimate an unbiased estimate of the effects of suffrage within this model. First, we require that there not be any confounding events with suffrage, which we discuss in detail in Section 3. Second, non-suffrage granting states must represent a plausible counterfactual for the outcomes in suffrage-granting states. Threats to identification, then, are any differential trends among states that are correlated with the passage of suffrage laws, which may also influence educational outcomes.

We begin by estimating the effects of the policy by age of exposure in an event-study specification. The advantage of this empirical approach is that it provides a natural test for the identification assumption of the model because any differential pre-trends can be examined visually. This specification also provides information regarding the linearity of the treatment effects, which may provide information regarding important mechanisms for the effects. ${ }^{41}$

or the states which had adequate death registration systems to provide statistics to the Bureau, grew from 10 states in 1900 to 48 states in 1933. See Miller (2008) for more detail regarding this data.

${ }^{37}$ Original pdf's can be downloaded from http://www.cdc.gov/nchs/products/vsus/vsus_1890_1938. htm.

${ }^{38}$ These data are sourced from the Biennial Survey of Education reports collected by the U.S. Office of Education from 1918 to 1966.

${ }^{39}$ We thank Shahar Sansani for providing us with these data, which build upon the data utilized in Sansani (2011).

${ }^{40}$ From 1918 onwards, these data are only available biennially. Missing years are imputed using linear interpolations.

${ }^{41}$ For example, a growing literature on in-utero exposure to public programs suggests that health improvements are most impactful prior to birth up to age 5. If our impacts are driven primarily by that mechanism, we might expect to see small effects at all ages except 0 to 5 (Hoynes et al., 2016). 
In particular, we estimate:

$$
Y_{r s E d_{i c s t}}=\beta_{0}+\sum_{a=-10}^{30} \beta_{a} \mathbb{1}\left(\text { AgeTreat }_{c s}=a\right)+\gamma_{1} X_{i c s t}+\gamma_{2} Z_{c s}+\theta_{c}+\delta_{s}+\chi_{s} * c+\tau_{c t}+\phi_{r c}+\epsilon_{i c s r t},
$$

where $i, c, s, r$, and $t$ represent individual, cohort, state of birth, region of birth, and

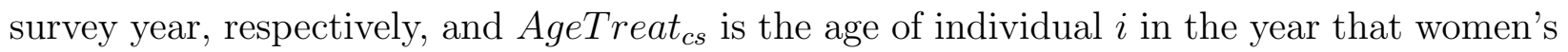
suffrage was passed in $s .^{42} \delta_{s}$ and $\theta_{c}$ flexibly control for differential political, education, and education climates across states and cohorts, respectively. A state-level trend, $\chi_{s} * c$, controls for linear changes in education at the state level across different years of birth, and cohort by survey year fixed effects, $\tau_{c t}$, further control for the aging of cohorts over time. We also include individual controls, $X_{i c s t}$, such as race, age, and gender, to absorb differences across demographic groups in educational attainment. Moreover, we add a variety of statecohort controls, $Z_{c s}$, to account for time-varying non-linear changes in state demographics, employment, income, and changes in education policy and availability. ${ }^{43,44}$

Finally, we include region by cohort fixed effects, $\phi_{r c}$, to control for unobservable differences across regions over time, which may be responsible for the regional spread of suffrage and correlated with education outcomes ${ }^{45}$ (Stephens and Yang, 2014).

The identifying variation for the coefficients of interest, $\beta_{a}$, is generated by differential exposure to suffrage within cohorts and across states (within regions), as well as within states and across cohorts. Figure 4 illustrates this variation. For parsimony, we group together states who passed suffrage in a short span from another. Moving along the line shows the variation across cohorts controlling for the year of suffrage (within-state variation), while the horizontal spread depicts the variation across states (within-cohort). Since the law never "turns off", the amount an individual is exposed to suffrage is collinear with the birth year and the year of suffrage. In terms of our identification, this implies that we cannot disentangle the effects of being exposed at an early age and being exposed for a longer period of time.

We plot the event studies for the ages of suffrage exposure from -10 and 30 . We set the treated age equal to " 30 " for all AgeTreat $c$ $\geq 30$ and to "-10" for all AgeTreat As $\leq-10 .{ }^{46}$ Grouping in this manner increases the precision of our estimates and allows us to estimate

\footnotetext{
${ }^{42}$ Formally, the age of exposure is measured as AgeTreat ${ }_{c s}=$ YearSuffrage $_{s}-c$.

${ }^{43}$ These controls include percentage white, percentage female, percentage foreign, percentage urban, percentage literate, population, real manufacturing wages, employment in manufacturing, real farm value, all measured at the year of birth, as well as measures of intensity of Rosenwald schools and compulsory schooling laws.

${ }^{44}$ We experiment with the sensitivity of our results to varying functional forms for these controls in Section 7 and find few differences across the specifications.

${ }^{45}$ We group states into four regions, West, Midwest, Northeast, and South, using the Census classification.

${ }^{46}$ Moreover, we group the age at treatment indicators into groups of two. For example, AgeTreat $c s=-10$ and AgeTreat $c s=-9$ both become AgeTreat $_{c s}=-9$, AgeTreat $_{c s}=-8$ and AgeTreat $_{c s}=-7$ both become AgeTreat $_{c s}=-7$, and so forth.
} 
state trends and region by birth cohort fixed effects without dropping additional event-time dummies. All coefficients are measured relative to the omitted category, AgeTreat ${ }_{c s}=30$.

Additionally, our baseline results are stratified by race to take account of the marked gaps in educational attainment and in human capital investments across black and white children during this period.

To summarize the treatment effects captured in the event study, we estimate an average effect of the laws using the following equation:

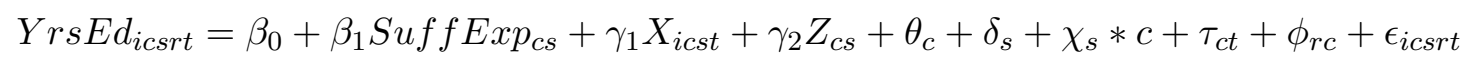

where $S u f f E x p$ is a measure of exposure to the suffrage laws. In our preferred specification, we define suffrage exposure as the share of time between birth and age 15 that women are able to vote in an individual's state of birth, PercentTreatBy $15_{\text {acs }}$. Formally,

$$
\text { PercentTreatBy } \left.15_{a c s}=\sum_{a=0}^{15} \frac{1(c+a>\text { YearSuffrage }}{s}\right)
$$

where YearSuffrage is the year in which suffrage was passed in the state. We define the relevant age of exposure ending at the typical school-leaving age, 15 years, ${ }^{47}$ at which point children are on the margin of leaving school and are susceptible to policy changes.

\section{Results}

We present the results for the event study specification separately by race in Figure 5, where we plot the estimated coefficients as well as their $95 \%$ confidence intervals against the age of treatment.

We begin by discussing the estimated effects for blacks, which are plotted in dark markers in Panel A of the figure. For this group, the figure shows that suffrage had small, insignificant effects for cohorts that were exposed to suffrage after age 15, and larger, positive, and statistically significant effects for black children that were exposed to suffrage at younger ages. ${ }^{48}$ The point estimates steadily increase as the age of exposure decreases, and stabilize

\footnotetext{
${ }^{47}$ Calculated as the sum of the median age that the typical child began school prior to suffrage, and the average years of schooling prior to suffrage, 7 and 8 years respectively. For blacks, the median school starting age was a bit higher, closer to 8 years old, but the average pre-period education was lower, at just over 5 years (Collins and Margo (2006) and author's calculations), suggesting that the relevant margin for blacks may be at a younger age. Importantly, since there is a wide distribution of school entry and leaving ages, these are only rough approximations, and we will use our event study specification as a data-driven way to validate the relevance of this margin.

${ }^{48}$ The observed effects on children on the margin of school-leaving in the year that suffrage was passed are consistent with the immediate, sharp increases in spending following suffrage (Lott and Kenny, 1999; Miller, 2008).
} 
for children exposed by age 5. For these "partially treated" as well as "fully treated" children born after the passage of suffrage, the effect of suffrage is roughly 1 year of additional education. $^{49}$

For the white sample, plotted in the unfilled markers in Panel B, the effects hover at zero and are flat at all ages of treatment. The null effect for this sample indicates that either the newly empowered white women did not, on average, use their enfranchisement to divert resources towards their community, or that the resources had little effect on the relatively more educated white children. In the following section, we test whether there are varying impacts within whites and blacks, which may allow us to rule out one of these explanations.

Importantly, the pattern of the coefficients is compelling evidence in favor of our empirical strategy. The flat coefficients for the sample treated after age 15, who had surpassed the marginal age of treatment, suggests that our effects are not capturing differential trends in educational attainment across cohorts. ${ }^{50}$ We consider this to be definitive and compelling evidence that our estimates are not tainted by endogenous adoption of the laws.

We now move away from the event studies towards the estimation of the average impact of exposure to suffrage, presented in Table 3. Overall, we find that full exposure to suffrage, from $0 \%$ to $100 \%$ of the period from age 0 to 15 , leads to a 0.07 increase in average years of schooling across the sample, although this treatment effect is not estimated with statistical precision. This is largely a reflection of the small effect for whites, for whom we find that full exposure to suffrage increased education by a statistically insignificant 0.03 years. For black children, on the other hand, we find that full exposure to suffrage produced gains of 1.07 years, an effect significant at the $1 \%$ level. At the mean level of black educational attainment, this increase represents about $16 \%$ gain in completed education. ${ }^{51}$

In the remaining four columns of Table 3 we analyze whether suffrage differentially improves outcomes for girls, a pattern shown in previous studies of female empowerment (Qian, 2008; Duflo, 2003). Suffrage may be viewed as increasing the value of daughters, directly through political power and indirectly by providing a mechanism through which women can improve their economic and social standing. As a result, the marginal returns to investment for parents would rise. Additionally, there may be a modeling effect for younger girls inspired by women's expanded political rights. The results do not appear to support either of these

\footnotetext{
${ }^{49}$ In Appendix Section A.1, we discuss the channels which may be responsible for generating this pattern of coefficients.

${ }^{50}$ We formally test for an effect of suffrage beyond age fifteen in Appendix Table A.1 by testing the effect of exposure between age 16 and 22 and between 23 and 30 as additional covariates. The measures of exposure at later stages are small in magnitude and not significant, while the coefficient on exposure between age 0 and 15 remains stable.

${ }^{51}$ We exclude individuals that did not qualify as neither white nor black from this subgroup analysis. The excluded sample is small, with only 4,592 observations.
} 
mechanisms. We find no statistically significant result for either of the white subsamples. For blacks, the point estimate is qualitatively similar across genders, although the point estimate for males is slightly higher than for females (1.2 compared with 0.92).

\subsection{Understanding Impacts Across Subgroups}

We begin to unpack the heterogeneous impacts of suffrage across race groups by analyzing whether suffrage also had larger effects for more disadvantaged individuals within racial groups.

In particular, we re-estimate equation (2) for a series of subgroups defined by region, race and gender. Figure 6 plots the coefficient estimates for PercentTreatBy15 from each of the coefficients against the mean education level for non-treated individuals in the subgroup, ${ }^{52}$ which we use as an indicator of the level of disadvantage for that subgroup. A clear negative relationship between the size of the coefficient and mean education emerges. In other words, subgroups with lower levels of pre-treatment education are shown to have large treatment effects, while subgroups with higher levels of pre-treatment education experience little or no effect following suffrage. We also notice that the impacts are no longer solely concentrated among black individuals. White boys and girls in the South, who have average educational attainment of 8 years at baseline, also experienced a positive effect of the policy. Full exposure to suffrage led to a 1 year increase in education for these subgroups, an effect size comparable to blacks with similar initial education levels. ${ }^{53}$

This figure illustrates clear differences in the impacts of suffrage across regions, which we quantify by running regressions separately for each region. In columns (1)-(4) of Table 4, we show that suffrage led to a significant positive effect on education for whites in the Northeast and the South, and for blacks in the Northeast, Midwest, and the South. ${ }^{54}$ The subsequent columns ((5)-(8)) confirm that our estimated effects for the sample of pooled regions are also not sensitive to dropping any of the regions. Appendix Figure A.3 confirms these regional patterns in an event study framework, and reveals that Southern whites experienced a similar pattern of treatment effects by age as blacks. ${ }^{55}$

\footnotetext{
${ }^{52}$ We define non-treated individuals as individuals who were age 16 or older at the time suffrage was passed in their state of birth.

${ }^{53}$ We perform the same exercise using other measures of advantage - share of individuals that own a home, share of individuals in urban locations, and average log income - and include the results in Appendix Figure A.2. The relationship is quite similar regardless of the metric used.

${ }^{54} \mathrm{We}$ also find a positive effect for blacks in the West, but the effects are highly imprecise due to the extremely small sample of blacks.

${ }^{55}$ These coefficients are estimated separately for whites and blacks using an event study specification that allows for differential coefficients for the age at treatment dummies for states in the South and outside of the South.
} 
Next, we formally test for a relationship between the effect size and the pre-treatment education by adding an interaction between PercentTreatBy15 and pre-treatment education. ${ }^{56}$ The main effect and the interaction are reported in Table 5. The coefficient on PercentTreatBy15, which represents the average effect for a group with zero pre-period education at baseline, is 1.23 for the whole sample. The coefficient on the interaction is negative and significant, which suggests that subgroups with higher pre-period levels of education benefited less from exposure to suffrage, consistent with Figure 6. In columns (2)-(5) we show the specification repeated within gender-race subgroups and find similar effects. This suggests that the impact of suffrage was near-universal at low levels of education across all races, but does not appear in the average effect for whites because of the composition of the sample.

\subsection{Impacts on the Distribution of Education}

To gain a richer understanding of the effects on attainment, we employ distributional methods to identify the margin of educational attainment most impacted by suffrage. Specifically, we look to estimate the effects of exposure to suffrage on the cumulative distribution function (CDF) of educational attainment (Duflo, 2001), and whether the treatment causes there to be an increase in the probability of having higher levels of education (1-CDF). In the case of a binary treatment, this simplifies to comparing the CDF of educational attainment for the untreated and treated groups; the difference represents the shift resulting from the policy. The same intuition can be extended to a continuous measure of treatment, such as in our context.

In practice, we estimate a progression of models in which we substitute the continuous education variable with a dummy that indicates whether the completed education of individual $i$ is greater than $p$ (1-CDF), where $p$ takes on the discrete values from 0 to 17 (Almond et al., 2011; Duflo, 2001). ${ }^{57,58}$

Panels A and B of Figure 7 plot the coefficients obtained from this estimation procedure for the black and white samples, respectively. For blacks, we find that the impact of suffrage on education attainment is concentrated between 4 and 6 years of education, while for whites we find small effects between 7 and 9 years of education. To check the alignment of these effects with the distribution of educational attainment, we also show the fraction of the

${ }^{56}$ To gain additional variation, we define pre-treatment education at the state, race, and gender cell.

${ }^{57}$ Specifically, we estimate:

$$
G_{i c s r t p}=\beta_{0}+\theta_{p} S u f f \operatorname{Exp}_{c s}+\gamma_{1} X_{i c s t}+\gamma_{2} Z_{c s}+\rho_{s}+\chi_{s} * c+\delta_{c} * \psi_{t}+\tau_{c t}+\phi_{r c}+\epsilon_{i c s r t},
$$

where $G_{i c s r t p}$ is a dummy that indicates whether the completed education of individual $i$ is greater than $p$.

${ }^{58}$ The Census does not allow reporting of attainment beyond 17 years. We do not believe this influences our estimation. 
population at each level of education at baseline. Now it becomes clear that largest impact appears close to the median for each group, 5 and 8 years for blacks and whites respectively. Thus, it appears that one of the main benefits of suffrage may have been to help raise the bottom and middle of the distribution of historically less educated communities.

\subsection{Literacy and the Labor Market Returns to Education}

The previous discussions focused on the impact of suffrage on the quantity of education attained. In this section, we examine whether the extended time in school led to the acquisition of literacy, and whether the impacts on education translated into gains in the labor market.

\subsubsection{Literacy}

We begin by analyzing the attainment of literacy, a crude measure of minimal human capital, which was collected by the Census until 1930. Since literacy is acquired with approximately three years of schooling (Collins and Margo, 2006), a margin surpassed by most children in our sample, we expect our estimates to be quite imprecise. Nonetheless, the event study in Figure 8 suggests that there were positive impacts on literacy, with up to a 5 percentage point increase for black children exposed at the youngest ages. The shape of the plot mimics the pattern of the coefficients for education, with small or zero effects for individuals exposed after age 16, increasing effects for children exposed during schooling age, and a relative flattening of the cumulative impact for children born when suffrage was already enacted. While the results are measured with error, this is suggestive evidence that suffrage led to improvements in literacy together with extended schooling.

\subsubsection{Labor Market Outcomes}

Next, we analyze whether suffrage impacted labor market outcomes, including the likelihood that an individual has non-zero income and the log of wage income. ${ }^{59}$ This estimation is restricted to a sample of individuals aged 30 to 60 years old. For the full sample, shown in Appendix Table A.2, we find little evidence that full exposure to suffrage during childhood led to an increase in the likelihood of having non-zero income and higher wages as adults. Given that the strongest effects of suffrage exposure on educational attainment were concentrated in the South, however, it is plausible that labor market effects were stronger in this

\footnotetext{
${ }^{59}$ In results not shown, we also analyze occupational income score, finding insignificant results. Occupational income score is obtained by assigning to each individual the median income of the persons with the same occupation as the individual.
} 
region as well. Hence in columns (3) and (6) of Appendix Table A.2 we allow for differential effects for states in the South and outside of the South. Using this specification, we find that full exposure to suffrage led to a statistically significant 31 percent increase in income for whites in the South, and a statistically insignificant effect on blacks and whites outside the South. These effects may include some increases in labor force participation in the South, however the effects are imprecise and we cannot reject zero effect on the extensive margin.

In order to confirm that these effects are not driven by differential trends across regions, we replicate these results in event study analyses of these labor market outcomes, stratifying by race and allowing for differential effects for Southern states. The results, shown in Figure 9 , confirm the positive effects of suffrage laws on the income of whites but not that of blacks. This may be because blacks, while gaining more years of education, encountered lower returns to skill in the labor market (Bleakley, 2007).

\subsection{Discussion of Mechanisms and Magnitude of Estimates}

We interpret our results as a reduced form effect of improvements in bargaining, health, and educational quality, each of which may have differentially improved the outcomes of less-advantaged groups. First, suffrage may increase the bargaining power of women in the household by reducing a woman's reliance on her husband. This channel may have contributed to the effects on white children, but is less plausible for disenfranchised black communities.

The second channel is through health improvements, facilitated through increased public spending and health projects, which influence the demand for education resulting from improvements in health. As a reminder, Miller (2008) finds that suffrage led to important declines in mortality among youth. We replicate his results, and further test whether suffrage led to differential changes in mortality across race and region of birth. ${ }^{60}$ We present these results in Appendix Table A.3, finding similarly large effects on mortality across race groups, and larger effects in the South. Thus, the larger impacts on education observed in the South may in part be due to greater improvements in health in that region, but differential effects on mortality do not appear to explain the race patterns outside of that region.

The link between health and cognition is well-established in the literature. Empirically, a relatively small decline in the mortality rate has been associated with substantial impacts on human capital accumulation due to the accompanying decline in disease burden among

\footnotetext{
${ }^{60}$ We focus our analysis on mortality of children aged 4-19, who were the groups most affected by suffrage exposure according to Miller (2008). These regressions are run on state-year-race cells, and include controls for state demographics, state and year fixed effects, and state linear time trends.
} 
surviving children. ${ }^{61}$ For example, Bhalotra and Venkataramani (2011) find that a shift in the pneumonia-induced infant mortality rate by 0.26 deaths per thousand increased the educational attainment of white men by 0.19 years on average (intent-to-treat). As a thought exercise, we rescale these treatment effects by the declines in infant mortality following suffrage found in Miller (2008), and find that over half the estimated effect of suffrage could be reconciled by improvements in health. ${ }^{62,63}$ Therefore, health improvements likely contributed to the increases in education, but are unlikely to completely account for the estimated impacts.

The third channel is through increases in educational expenditures following suffrage, which had the capability to reinforce and support increased demand for education. Carruthers and Wanamaker (2014) estimate a 20 to $29 \%$ increase in educational spending following the passage of suffrage. We contribute to evidence of this channel by investigating effects on school quality, an important route by which increased educational expenditures following suffrage may have affected educational attainment. Our newly assembled stateyear panel of average pupil-teacher ratio and school term length from 1900-1930 allows us to test this hypothesis for the full sample of states. The sparsity of available data causes us to use an unbalanced panel for this analysis, which we raise as a caveat to the approach. ${ }^{64}$ The estimates in Panel A of Appendix Table A.4 indicate that suffrage is associated with a small and statistically insignificant decrease in the pupil teacher ratio, a small statistically insignificant impact on term length outside the South, and a large and significant positive effect on term length in the South. ${ }^{65}$ Again, these improvements in school quality may have contributed to the larger treatment effects observed in the South: ${ }^{66}$ we are cautious not to

\footnotetext{
${ }^{61}$ In theory, the magnitude of the impacts from this channel have been depend on the role of selective mortality (increased survival of weak individuals) relative to other health gains, as the two processes have opposing implications for education outcomes.

${ }^{62}$ Miller (2008) finds that suffrage led to a a reduction in mortality of 0.95 per 1,000 among infants and young children ( $8 \%$ relative to baseline). Using the estimates from Bhalotra and Venkataramani (2011), this reduction in mortality translates into a $0.69\left(\frac{.95}{.26} * .19\right)$ increase in years of education. Estimates from other health interventions during this period suggest that this may be a conservative estimate of the influence of health on education (e.g. Barreca (2010)). This exercise relies on the assumption that reductions in mortality have linear effects on the human capital of the surviving population, including selection effects.

${ }^{63}$ The passage of suffrage did not affect mortality from pneumonia, however suffrage-linked sanitation improvements combated a similarly deadly suite of infectious diseases (diarrhea, meningitis, diphtheria).

${ }^{64}$ These variables are only available for all 12 states in all years.

${ }^{65} \mathrm{We}$ additionally test for breaks in trends following suffrage in Panel B, and find no such evidence.

${ }^{66}$ We explore the differential effects of suffrage by race on education quality in the South as measured by pupil teacher ratio, term length and teacher salary, and present the results in the Appendix Table A.5. These data were obtained from Card and Krueger (1992) and are available only for the Southern states and Missouri starting from 1915 onwards, which restricts the validity of the estimates to those states. With that caveat in mind, we find suggestive evidence that term length and teacher salary increased following suffrage for both blacks and whites, with larger effects for whites, consistent with Carruthers and Wanamaker (2014). However, the pupil teacher ratio decreased for blacks while it increased for whites. This could be due to the
} 
overemphasize this point, however, since we are not able to measure key features of schooling, such as the distance to the nearest school, and our use of state variation in school quality may obscure local changes in schooling investments outside the South.

The multiple-pronged treatment resulting from suffrage generated educational gains similar to other notable educational interventions. The closely timed Rosenwald initiative, for example, was found to improve education of black children by a similar magnitude to suffrage (Aaronson and Mazumder, 2011). These sizable educational gains are not limited to interventions at the turn of the $20^{\text {th }}$ century. The effects of suffrage are akin to the one year increase in the attainment of black students from court-ordered desegregation (Johnson, 2015), somewhat larger than the 0.6 additional years of attainment from a decrease in the pupil-teacher ratio by 10 students (Card and Krueger, 1992), and similar to the 0.9 year increase in attainment of children from poor families resulting from a $20 \%$ increase in per-pupil spending (Jackson et al., 2015). Interestingly, the income gains resulting from an increase in per-pupil spending $(24.6 \%)$ are also similar to the effects we estimate in the South $(30 \%)$.

\section{Robustness}

In this section, we conduct a variety of robustness exercises to address potential concerns and alternative explanations for our estimates.

\subsection{Endogenous Passage of Laws}

If the timing of passage of the suffrage laws is correlated with pre-existing trends in education or with other state-level policies, then a naive specification could mis-attribute the trend or the effects of simultaneously evolving programs as measured effects of suffrage. The event study estimates provide compelling visual confirmation that this is not the case, bolstered by the finding that the timing of suffrage laws is independent of other state-level policies.

As a final piece of evidence, we estimate an additional specification where we add an interaction between the measure of suffrage exposure and whether the state adopted suffrage involuntarily. Finding positive effects for voluntary states only would be worrisome, as it would suggest that the results are biased by endogenous adoptions of suffrage laws. Instead, our results shown in Table 6 shows that suffrage had a statistically significant larger effect in involuntary states compared to voluntary states, which is the opposite of what we would differential use of the increased spending by black and white schools. 
expect if the timing of suffrage laws was endogenous. We do not place much emphasis on the magnitude of the difference, however, as we believe it is likely driven by the differing composition of the samples across the two sets of states. The results for our event study specification, modified to include an interaction with indicators for mandatory and nonmandatory states, are presented in Appendix Figure A.4. The point estimates are quite imprecise and therefore do not provide conclusive evidence for this analysis, but the effects of suffrage appear similar for the two groups of states.

\subsection{Selective Migration}

An additional concern is whether selective migration might be influencing our estimates. If later cohorts in a state who have higher levels of suffrage treatment are also more likely to migrate to areas with higher investments in education, there may be a correlation between migration decisions and suffrage which would introduce bias to our estimates. This is of particular concern for our study due to the overlap between our period of observation with the Great Migration movement, during which over a million black individuals moved from the South to northern cities (Chay and Munshi, 2012). In our favor, prior studies suggest that there were only small, positive selection effects of the Great Migration (Collins and Wanamaker, 2014), limiting the scope for bias, but that does not preclude the possibility of other selective migration.

We can check for this type of bias by simply estimating our preferred specification separately by migration status of individuals. If migration is a source of positive bias, we would expect our results to be largest among individuals that migrated compared to those that did not. We check for this by stratifying our sample by "Movers", individuals observed in a different state from their state of birth, and "Non Movers", and display our results in Table 7. For blacks, we find that the point estimate is substantially the same as our previous estimate among non movers, and it is not statistically different from zero for movers. These estimates do not suggest a role for selective migration, but rather are reconcilable by measurement error. For some proportion of movers, we have likely mis-assigned treatment time by using suffrage laws enacted in the state of birth, which would result in the observed attenuation.

\subsection{Alternative controls}

Properly controlling for confounding variation across cohorts, such as secular changes in education, technology, and economic development, is of utmost importance to the analysis. At the same time, we do not want to control for endogenous changes, which would bias our estimates. In our main analysis, we strike a compromise by including proxies for these 
factors measured at birth. In Appendix Table A.6, we test the sensitivity of our results to this decision. In Column (1) we replicate our main results, showing the results for the whole sample in Panel A, the black sample in Panel B, and the white sample in Panel C. In Column (2), we include the same control variables, but now averaged between ages 0 to 15. This specification better reflects the environment that children experience during schooling, but potentially introduces endogenous controls if some of the environment was shaped by the passage of suffrage. The coefficients are similar across Columns (1) and (2), with a slight decline in the coefficient for the black subsample. In Column (3), instead, we interact the level of the control variables in 1900 with a linear trend (Hoynes et al., 2016). Here we run the risk of under-controlling for confounding variation. Again, the coefficients are steady. Overall, we are reassured that the estimates are not sensitive to the functional form of our controls.

\subsection{World War II and the G.I. bill}

It is difficult to discuss growth in educational outcomes in the early twentieth century without mention of World War II and the G.I. bill, each of which had a strong influence on the educational decisions of the cohorts coming of age during that era. ${ }^{67}$ The G.I. Bill provided federal financial support for veterans returning from war and has been credited with increasing the college completion rate by up to $50 \%$ (Bound and Turner, 2002). Studies of the effects of the bill often take advantage of the variation in the proportion serving across cohorts, comparing the cohorts with high participation rates, born between 1921 and 1926, to nearby cohorts. Due to the overlap in the cohorts in our sample and the veterans impacted by the G.I. Bill, the effects of this policy pose a potential risk as a confounder, especially if there is additional variation in mobilization rates across states. However, given that our effects are entirely concentrated in primary and secondary schooling, subsidies to college would be an unlikely explanation. In addition, Turner and Bound (2003) find that for blacks living in the South, one of the groups that most benefited from suffrage, the GI bill has no effect, which adds to the inconsistency. Nevertheless, we check for any correlation between mobilization rates and the timing of suffrage in case there was an externality of participation in the war on primary education. We present the results in Appendix Table A.7. Controlling for regional dummies, we do not find any significant relationship between the year of suffrage and the proportion serving in WW2 in the state. Based on these two

\footnotetext{
${ }^{67}$ Early cohorts in our sample born from 1880 to 1900 were also eligible to serve during the First World War. Since these cohorts are concentrated among our "control group", we can look for evidence of bias from the War in the form of pre-trend for the children too old to experience the benefits of suffrage. Our event studies show no evidence of this, however, indicating that any effect of the War is absorbed by our control variables.
} 
discrepancies, we find no role for the G.I. bill in our estimates.

\subsection{Additional checks}

In Appendix Tables A.8 and A.9 we check the sensitivity of our results to utilizing a binary measure for exposure between the ages of 0 and 15 and to running our preferred specification separately by census year. As might be expected, using a dummy for exposure simply produces a weighted average of the effects in the event study. This turns out to be about 0.3 , or one third the size of our previously estimated effect, due to the nonlinearity of the point estimates across ages. Finally, we find the results are generally unchanged across census samples, although there is attenuation in the 1940 census consistent with the measurement anomalies reported in previous studies (Goldin, 1998). We provide additional checks of the sensitivity of our results to including trends in the pre-treatment education levels, dropping compulsory law controls and adding controls for progressive laws in Appendix Table A.10, and document the relative insensitivity of our coefficients to the addition of our controls in the Online Appendix. ${ }^{68}$

\section{Conclusion}

This paper presents new evidence on the effects of women's political empowerment on investments in children's human capital. We find that exposure to the post-suffrage regime during childhood leads to substantial gains in educational attainment, concentrated amongst populations with low levels of education at baseline. In particular, full exposure to suffrage between age 0 and 15 leads to approximately one year of additional education for blacks, and for whites from the South, the least advantaged groups in the sample. Our effects are concentrated in primary schooling, which is the mean educational attainment of the affected groups. This suggests that the policies resulting from suffrage were effective at raising the attainment of students at the lower half of the education distribution, and led to the convergence of educational outcomes. Using literacy as a proxy for skills attained, we provide suggestive evidence that these gains in quantity of education translated into improved human capital. Moreover, we show that suffrage led to gains in the labor market among white children with the greatest improvements in education.

We examine the channels by which suffrage induced improvements in education, attributing a large share of the impact to the sharp rise in public expenditures following enfranchisement. This finding is in line with the the impacts of a number of other transfers of economic

\footnotetext{
${ }^{68}$ See Table OA.6.
} 
and political resources to women, and highlights an important commonality between the two types of transfers. While suffrage did not represent an increase in the economic holdings of women, the greater ability to influence public spending indirectly had the equivalent effect. This result is also consistent with other interventions timed closely with suffrage, which find a strong role for public and philanthropic investments in improving educational outcomes. One limitation of this finding is that we are not able to disentangle the effects of the increase in health, social, and education expenditures, as well as accompanying legislation, that accumulated as a result of suffrage.

This article quantifies the effects of political empowerment of women in the United States. However, parallels between these results and modern interventions suggest that the channels we highlight would translate to other settings. In particular, there is growing evidence that public expenditures in contemporary settings also produce the largest gains for children with the lowest baseline educational attainment. A recent paper, Jackson et al. (2015), suggests that education expenditures produce substantial effects on educational attainment for children from poor families and no effect on children from non-poor families. Similar patterns are emerging from studies of Food Stamps, WIC, Medicaid, and Head Start (Almond et al., 2011; Hoynes et al., 2011; Currie and Gruber, 1996; Bitler et al., 2014).

On the whole, this article provides compelling evidence for the role of female voter preferences in influencing policy. As political power increasingly equates to economic holdings, a future promising avenue for research is to understand whether women's economic power can lead to similar gains. This research is already advancing in the developing world, and the results for children are promising (Qian, 2008). However, a large gap remains in the developed context, where questions remain whether advances in the relatively smaller gap between men and women would have any impact on educational outcomes. Nonetheless, this question is of great relevance today given the push for gender equality in the workplace, highlighted as a policy priority in the recent presidential State of the Union address (Obama, 2015). We leave it for future research to provide evidence in this area. 


\section{References}

Aaronson, D. and Mazumder, B. (2011). The Impact of Rosenwald Schools on Black Achievement. Journal of Political Economy, 119(5):821-888.

Acemoglu, D. and Angrist, J. (2001). How Large are Human-Capital Externalities? Evidence from Compulsory-Schooling Laws. NBER Macroeconomics Annual 2000, 15:9-74.

Acemoglu, D., Autor, D. H., and Lyle, D. (2004). Women, War, and Wages: The Effect of Female Labor Supply on the Wage Structure at Midcentury. Journal of Political Economy, 112(3):497-551.

Aidt, T. S. and Dallal, B. (2008). Female Voting Power: The Contribution of Women's Suffrage to the Growth of Social Spending in Western Europe (1869-1960). Public Choice, 134(3-4):391-417.

Almond, D., Hoynes, H. W., and Schanzenbach, D. W. (2011). Inside the War on Poverty: The Impact of Food Stamps on Birth Outcomes. Review of Economics and Statistics, 93(2):387-403.

Baker, P. (1984). The Domestication of Politics: Women and American Political Society, 1780-1920. The American Historical Review, 89(3):pp. 620-647.

Barreca, A. I. (2010). The Long-Term Economic Impact of In Utero and Postnatal Exposure to Malaria. Journal of Human Resources, 45(4):865-892.

Bhalotra, S. R. and Venkataramani, A. (2011). The Captain of The Men of Death and His Shadow: Long-run Impacts of Early Life Pneumonia Exposure. Working Paper.

Bitler, M. P., Hoynes, H. W., and Domina, T. (2014). Experimental Evidence on Distributional Effects of Head Start. Working Paper 20434, National Bureau of Economic Research.

Bleakley, H. (2007). Disease and Development: Evidence from Hookworm Eradication in the American South. The Quarterly Journal of Economics, 122(1):73-117.

Bound, J. and Turner, S. (2002). Going to War and Going to College: Did World War II and the G.I. Bill Increase Educational Attainment for Returning Veterans? Journal of Labor Economics, 20(4):784-815. 
Braun, S. and Kvasnicka, M. (2013). Men, Women, and the Ballot: Gender Imbalances and Suffrage Extensions in the United States. Explorations in Economic History, 50(3):405426.

Card, D. and Krueger, A. B. (1992). Does School Quality Matter? Returns to Education and the Characteristics of Public Schools in the United States. Journal of Political Economy, 100(1):1-40.

Carruthers, C. K. and Wanamaker, M. H. (2013). Closing the Gap? The Effect of Private Philanthropy on the Provision of African-American Schooling in the U.S. South. Journal of Public Economics, 101:53-67.

Carruthers, C. K. and Wanamaker, M. H. (2014). Municipal Housekeeping: The Impact of Women's Suffrage on the Provision of Public Education. Journal of Human Resources.

Cascio, E. U. and Washington, E. (2013). Valuing the Vote: The Redistribution of Voting Rights and State Funds Following the Voting Rights Act of 1965*. The Quarterly Journal of Economics, pages 379-433.

Chattopadhyay, R. and Duflo, E. (2004). Women as Policy Makers: Evidence from a Randomized Policy Experiment in India. Econometrica, 72(5):1409-1443.

Chay, K. and Munshi, K. (2012). Black Networks After Emancipation: Evidence from Reconstruction and the Great Migration. Technical report, Mimeo.

Clots-Figueras, I. (2012). Are Female Leaders Good for Education? Evidence from India. American Economic Journal: Applied Economics, 4(1):212-44.

Collins, W. J. and Margo, R. A. (2006). Chapter 3 Historical Perspectives on Racial Differences in Schooling in the United States. In Welch, E. H. a. F., editor, Handbook of the Economics of Education, volume 1, pages 107-154. Elsevier.

Collins, W. J. and Wanamaker, M. H. (2014). The Great Migration in Black and White: New Evidence on the Selection and Sorting of Southern Migrants.

Cunha, F. and Heckman, J. (2007). The Technology of Skill Formation. American Economic Review, 97(2):31-47.

Currie, J. and Gruber, J. (1996). Saving Babies: The Efficacy and Cost of Recent Changes in the Medicaid Eligibility of Pregnant Women. Journal of Political Economy, 104(6):126396. 
Dahlin, E. C., Cornwall, M., and King, B. G. (2005). Winning Woman Suffrage One Step at a Time: Social Movements and the Logic of the Legislative Process. Social Forces, 83(3).

Depew, B., Edwards, G., and Owens, E. (2013). Alcohol Prohibition and Infant Mortality. Technical report, Mimeo.

Dixit, A. and Londregan, J. (1996). The Determinants of Success of Special Interests in Redistributive Politics. The Journal of Politics, 58(4):1132-1155.

Doepke, M. and Tertilt, M. (2009). Women's Liberation: What's in It for Men? The Quarterly Journal of Economics, 124(4):1541-1591.

Duflo, E. (2001). Schooling and Labor Market Consequences of School Construction in Indonesia: Evidence from an Unusual Policy Experiment. American Economic Review, 91(4):795-813.

Duflo, E. (2003). Grandmothers and Granddaughters: Old-Age Pensions and Intrahousehold Allocation in South Africa. The World Bank Economic Review, 17(1):1-25. 00886.

Duflo, E. (2012). Women Empowerment and Economic Development. Journal of Economic Literature, 50(4):1051-1079.

Engerman, S. L. and Sokolof, K. L. (2005). The Evolution of Suffrage Institutions in the New World. The Journal of Economic History, 65:891-921.

Ferreira, F. and Gyourko, J. (2014). Does Gender Matter for Political Leadership? The case of U.S. mayors. Journal of Public Economics, 112:24-39.

Goldin, C. (1998). America's Graduation from High School: The Evolution and Spread of Secondary Schooling in the Twentieth Century. The Journal of Economic History, 58(02):345-374.

Goldin, C. and Katz, L. (2003). Mass Secondary Schooling and the State. Working Paper 10075, National Bureau of Economic Research.

Goldin, C. and Katz, L. F. (2010). The Race between Education and Technology. Belknap Press, Cambridge, Mass.

Green, E. C. (1997). Southern Strategies: Southern Women and the Woman Suffrage Question. The University of North Carolina Press, Chapel Hill, 1 edition edition.

Heckman, J. J. (2007). The Economics, Technology, and Neuroscience of Human Capability Formation. Proceedings of the National Academy of Sciences, 104(33):13250-13255. 
Hoynes, H., Page, M., and Stevens, A. H. (2011). Can Targeted Transfers Improve Birth Outcomes?: Evidence From the Introduction of the WIC Program. Journal of Public Economics, 95(7-8):813-827.

Hoynes, H., Schanzenbach, D. W., and Almond, D. (2016). Long Run Impacts of Childhood Access to the Safety Net. American Economic Review, 106(4):903-34.

Jackson, C. K., Johnson, R. C., and Persico, C. (2015). The Effects of School Spending on Educational and Economic Outcomes: Evidence from School Finance Reforms. Working Paper 20847, National Bureau of Economic Research.

Johnson, R. C. (2015). Long-run Impacts of School Desegregation \& School Quality on Adult Attainments. Working Paper 16664, National Bureau of Economic Research.

Kantor, S. E. and Fishback, P. V. (1996). Precautionary Saving, Insurance, and the Origins of Workers' Compensation. Journal of Political Economy, 104(2):419-442.

Lemons, J. S. (1973). The Woman Citizen: Social Feminism in the 1920s. University of Illinois Press, first edition edition edition.

Lleras-Muney, A. (2002). Were Compulsory Attendance and Child Labor Laws Effective? An Analysis from 1915 to 1939. Journal of Law and Economics, 45(2):401-35.

Lott, J. R. and Kenny, L. W. (1999). Did Women's Suffrage Change the Size and Scope of Government? Journal of Political Economy, 107(6):1163-1198.

Lundberg, S. J., Pollak, R. A., and Wales, T. J. (1997). Do Husbands and Wives Pool Their Resources? Evidence from the United Kingdom Child Benefit. The Journal of Human Resources, 32(3):463-480. 01035.

Miller, G. (2008). Women's Suffrage, Political Responsiveness, and Child Survival in American History. The Quarterly Journal of Economics, 123(3):1287-1327.

Moehling, C. M. and Thomasson, M. A. (2012). The Political Economy of Saving Mothers and Babies: The Politics of State Participation in the Sheppard-Towner Program. The Journal of Economic History, 72(01):75-103.

Naidu, S. (2012). Suffrage, Schooling, and Sorting in the Post-Bellum U.S. South. Working Paper 18129, National Bureau of Economic Research.

Obama, B. (2010). Presidential Proclamation. Presidential Proclamation - Women's Equality Day, 2013. 
Obama, B. (2015). State of the Union Address. Remarks by President Obama in State of the Union Address to Congress, Washington, D.C.

Qian, N. (2008). Missing Women and the Price of Tea in China: The Effect of Sex-Specific Earnings on Sex Imbalance. The Quarterly Journal of Economics, 123(3):1251-1285. 00219.

Ruggles, S., Alexander, J. T., Flood, S., Goeken, R., Schroeder, M. B., and Sobek, M. (2010). Integrated Public Use Microdata Series: Version 5.0 [Machine-readable database].

Sansani, S. (2011). The Effects of School Quality on Long-term Health. Economics of Education Review, 30(6):1320-1333.

Skocpol, T. (1992). Protecting Soldiers and Mothers: The Political Origins of Social Policy in United States. Belknap Press, Harvard.

Stephens, Jr., M. and Yang, D.-Y. (2014). Compulsory Education and the Benefits of Schooling. American Economic Review, 104(6):1777-92.

Thomas, D. (1990). Intra-Household Resource Allocation: An Inferential Approach. The Journal of Human Resources, 25(4):635-664. 01549.

Thomas, D. (1993). The Distribution of Income and Expenditure within the Household. Annales d'conomie et de Statistique, (29):109-135.

Turner, S. and Bound, J. (2003). Closing the Gap or Widening the Divide: The Effects of the G.I. Bill and World War II on the Educational Outcomes of Black Americans. The Journal of Economic History, 63(1):145-177.

Walker, M., Dunn, J. R., and Dunn, J. P. (2003). Southern Women at the Millennium: A Historical Perspective. University of Missouri Press.

Wheeler, M. S., editor (1995). One Woman, One Vote: Rediscovering the Women's Suffrage Movement. NewSage Press, Alexandria, VA. 


\section{Tables}

Table 1: Estimated Changes in State Observables After Suffrage

\begin{tabular}{|c|c|c|c|c|c|c|}
\hline & \% White & $\%$ Urban & Pop. & Farm Value & Man. Empl. & Man. Wages \\
\hline \multicolumn{7}{|c|}{ A: Post (States with suffrage passed $>=1917$ ) } \\
\hline \multirow[t]{2}{*}{ Post Suffrage } & 0.01 & -0.01 & 3.77 & $-2.63^{*}$ & $0.16^{* *}$ & -1.40 \\
\hline & $(0.02)$ & $(0.04)$ & $(6.73)$ & $(1.52)$ & $(0.08)$ & $(0.88)$ \\
\hline Mean Y & 88.85 & 50.85 & 4477.77 & 111.85 & 3.99 & 29.56 \\
\hline Observations & 576 & 576 & 576 & 576 & 576 & 576 \\
\hline \multicolumn{7}{|c|}{ B: Post (States with suffrage passed $>=1918$ ) } \\
\hline \multirow[t]{2}{*}{ Post Suffrage } & 0.01 & -0.06 & 0.90 & $-2.10^{*}$ & 0.09 & -0.32 \\
\hline & $(0.02)$ & $(0.05)$ & $(4.07)$ & $(1.24)$ & $(0.13)$ & $(0.47)$ \\
\hline Mean Y & 87.60 & 47.35 & 3724.71 & 112.72 & 3.20 & 23.02 \\
\hline Observations & 496 & 496 & 496 & 496 & 496 & 496 \\
\hline \multicolumn{7}{|c|}{ C: Post and Change in Trend (States with suffrage passed $>=1918$ ) } \\
\hline \multirow[t]{2}{*}{ Post Suffrage } & -0.02 & -0.02 & -18.08 & $-7.06^{* *}$ & 0.15 & -0.31 \\
\hline & $(0.07)$ & $(0.18)$ & $(17.22)$ & $(3.15)$ & $(0.21)$ & $(0.65)$ \\
\hline \multirow[t]{2}{*}{ Post Suffrage Trend } & -0.06 & 0.07 & -34.81 & $-9.27^{* *}$ & 0.11 & 0.01 \\
\hline & $(0.09)$ & $(0.26)$ & $(26.94)$ & $(3.90)$ & $(0.15)$ & $(0.88)$ \\
\hline Mean Y & 87.60 & 47.35 & 3724.71 & 112.72 & 3.20 & 23.02 \\
\hline Observations & 496 & 496 & 496 & 496 & 496 & 496 \\
\hline
\end{tabular}

Notes: The states that passed suffrage laws in 1917 are: Arkansas, Nebraska, New York, North Dakota, Rhode Island. State observables are available biennially starting in 1915, missing years are linearly interpolated. We restrict the analysis to 1915 to 1930 to allow for lagged effects after the passage of suffrage. Post suffrage is a dummy variable that takes the value of one if the state passed the suffrage by the current year. Post suffrage trend captures a break in the trend after suffrage was passed in a state. All regressions include state fixed effects, state trends, and region-byyear fixed effects. Estimates are weighted using population weights, and standard errors are clustered on the state. Sources: Lleras-Muney (2002). ${ }^{*} \mathrm{p}<0.10,{ }^{* *} \mathrm{p}<0.05,{ }^{* * *} \mathrm{p}<0.01$. 
Table 2: Sample Demographic and State Characteristics

\begin{tabular}{|c|c|c|c|c|c|c|c|c|c|c|}
\hline & \multicolumn{2}{|c|}{ All } & \multicolumn{2}{|c|}{ Northeast } & \multicolumn{2}{|c|}{ Midwest } & \multicolumn{2}{|c|}{ South } & \multicolumn{2}{|c|}{ West } \\
\hline & $\mathrm{B}$ & W & $\mathrm{B}$ & W & $\mathrm{B}$ & W & $\mathrm{B}$ & $\mathrm{W}$ & $\mathrm{B}$ & W \\
\hline \multicolumn{11}{|l|}{ Individual Demographics } \\
\hline Years of Education & $\begin{array}{c}6.76 \\
(3.80)\end{array}$ & $\begin{array}{c}9.96 \\
(3.31)\end{array}$ & $\begin{array}{c}9.41 \\
(3.23)\end{array}$ & $\begin{array}{l}10.30 \\
(3.08)\end{array}$ & $\begin{array}{c}9.41 \\
(3.33)\end{array}$ & $\begin{array}{l}10.24 \\
(3.06)\end{array}$ & $\begin{array}{c}6.45 \\
(3.73)\end{array}$ & $\begin{array}{c}9.12 \\
(3.66)\end{array}$ & $\begin{array}{l}10.38 \\
(3.55)\end{array}$ & $\begin{array}{l}11.02 \\
(3.21)\end{array}$ \\
\hline Age & $\begin{array}{c}42.14 \\
(13.41)\end{array}$ & $\begin{array}{c}43.03 \\
(13.71)\end{array}$ & $\begin{array}{c}40.16 \\
(12.54)\end{array}$ & $\begin{array}{c}42.53 \\
(13.47)\end{array}$ & $\begin{array}{c}41.18 \\
(13.16)\end{array}$ & $\begin{array}{c}43.99 \\
(13.98)\end{array}$ & $\begin{array}{c}42.32 \\
(13.46)\end{array}$ & $\begin{array}{c}42.76 \\
(13.64)\end{array}$ & $\begin{array}{c}38.32 \\
(11.38)\end{array}$ & $\begin{array}{c}40.32 \\
(12.91)\end{array}$ \\
\hline Female & $\begin{array}{c}0.53 \\
(0.50)\end{array}$ & $\begin{array}{c}0.51 \\
(0.50)\end{array}$ & $\begin{array}{c}0.52 \\
(0.50)\end{array}$ & $\begin{array}{c}0.51 \\
(0.50)\end{array}$ & $\begin{array}{c}0.51 \\
(0.50)\end{array}$ & $\begin{array}{c}0.51 \\
(0.50)\end{array}$ & $\begin{array}{c}0.53 \\
(0.50)\end{array}$ & $\begin{array}{c}0.51 \\
(0.50)\end{array}$ & $\begin{array}{c}0.53 \\
(0.50)\end{array}$ & $\begin{array}{c}0.50 \\
(0.50)\end{array}$ \\
\hline Percent 0-15 Treated & $\begin{array}{c}0.45 \\
(0.42)\end{array}$ & $\begin{array}{c}0.47 \\
(0.43)\end{array}$ & $\begin{array}{c}0.59 \\
(0.42)\end{array}$ & $\begin{array}{c}0.47 \\
(0.42)\end{array}$ & $\begin{array}{c}0.57 \\
(0.44)\end{array}$ & $\begin{array}{c}0.46 \\
(0.43)\end{array}$ & $\begin{array}{c}0.43 \\
(0.41)\end{array}$ & $\begin{array}{c}0.45 \\
(0.42)\end{array}$ & $\begin{array}{c}0.79 \\
(0.35)\end{array}$ & $\begin{array}{c}0.72 \\
(0.39)\end{array}$ \\
\hline \multicolumn{11}{|l|}{ State-level Controls At Birth } \\
\hline Percent Urban & $\begin{array}{c}0.12 \\
(0.18)\end{array}$ & $\begin{array}{c}0.19 \\
(0.28)\end{array}$ & $\begin{array}{c}0.39 \\
(0.38)\end{array}$ & $\begin{array}{c}0.28 \\
(0.37)\end{array}$ & $\begin{array}{c}0.27 \\
(0.30)\end{array}$ & $\begin{array}{c}0.17 \\
(0.26)\end{array}$ & $\begin{array}{c}0.09 \\
(0.14)\end{array}$ & $\begin{array}{c}0.10 \\
(0.15)\end{array}$ & $\begin{array}{c}0.35 \\
(0.32)\end{array}$ & $\begin{array}{c}0.26 \\
(0.30)\end{array}$ \\
\hline Percent Literate & $\begin{array}{c}0.78 \\
(0.12)\end{array}$ & $\begin{array}{c}0.91 \\
(0.09)\end{array}$ & $\begin{array}{c}0.95 \\
(0.01)\end{array}$ & $\begin{array}{c}0.94 \\
(0.01)\end{array}$ & $\begin{array}{c}0.96 \\
(0.02)\end{array}$ & $\begin{array}{c}0.96 \\
(0.02)\end{array}$ & $\begin{array}{c}0.76 \\
(0.11)\end{array}$ & $\begin{array}{c}0.81 \\
(0.11)\end{array}$ & $\begin{array}{c}0.95 \\
(0.05)\end{array}$ & $\begin{array}{c}0.94 \\
(0.07)\end{array}$ \\
\hline Value of farm per acre & $\begin{array}{c}44.38 \\
(54.54)\end{array}$ & $\begin{array}{c}83.26 \\
(82.52)\end{array}$ & $\begin{array}{c}67.77 \\
(42.62)\end{array}$ & $\begin{array}{c}63.57 \\
(45.23)\end{array}$ & $\begin{array}{l}140.36 \\
(92.74)\end{array}$ & $\begin{array}{c}128.98 \\
(100.03)\end{array}$ & $\begin{array}{c}37.17 \\
(45.14)\end{array}$ & $\begin{array}{c}47.38 \\
(57.58)\end{array}$ & $\begin{array}{l}109.97 \\
(87.64)\end{array}$ & $\begin{array}{c}73.25 \\
(76.37)\end{array}$ \\
\hline Annual Manufacturing Wages & $\begin{array}{c}6.30 \\
(13.24)\end{array}$ & $\begin{array}{c}19.71 \\
(23.72)\end{array}$ & $\begin{array}{c}51.58 \\
(26.15)\end{array}$ & $\begin{array}{c}44.69 \\
(26.07)\end{array}$ & $\begin{array}{c}21.64 \\
(18.61)\end{array}$ & $\begin{array}{c}15.54 \\
(15.80)\end{array}$ & $\begin{array}{c}2.97 \\
(2.06)\end{array}$ & $\begin{array}{c}3.13 \\
(2.16)\end{array}$ & $\begin{array}{l}10.54 \\
(7.88)\end{array}$ & $\begin{array}{c}7.27 \\
(7.10)\end{array}$ \\
\hline Observations & 157028 & 1393855 & 7381 & 397080 & 8128 & 509551 & 140982 & 421211 & 537 & 66013 \\
\hline
\end{tabular}

Notes: "B" is an indication for the black subsample; "W" is an indication for the white subsample. Standard deviations are shown in parentheses. Percent 0-15 treated is defined as the share of time between birth and age 15 that an individual was exposed to a suffrage law in his state of birth. Farm value and wages are calculated in 100's of thousands. All monetary values are adjusted to 1982-84 dollars. The sample consists of individuals born between 1880 and 1930, and that are at least 20 years old at the time of observation. We exclude states that passed suffrage prior to 1900. Source: 1940-1960 decennial censuses. 
Table 3: Baseline Estimates of the Effect of Suffrage on Years of Education

\begin{tabular}{|c|c|c|c|c|c|c|c|}
\hline & & & & \multicolumn{2}{|c|}{ Whites } & \multicolumn{2}{|c|}{ Blacks } \\
\hline & All & Whites & Blacks & Males & Females & Males & Females \\
\hline \multirow[t]{2}{*}{ Suff Share 0-15 } & 0.072 & 0.027 & $1.067^{* * *}$ & 0.006 & 0.043 & $1.195^{* *}$ & $0.921^{* * *}$ \\
\hline & $(0.217)$ & $(0.204)$ & $(0.251)$ & $(0.193)$ & $(0.224)$ & $(0.580)$ & $(0.225)$ \\
\hline Mean Education & 9.634 & 9.958 & 6.759 & 9.840 & 10.072 & 6.351 & 7.126 \\
\hline Observations & 1555475 & 1393855 & 157028 & 688363 & 705492 & 74351 & 82677 \\
\hline
\end{tabular}

Notes: This table contains results obtained when the dependent variable is years of education and the main independent variable is suffrage exposure, which is defined as the share of time between birth and age 15 that an individual was exposed to a suffrage law in his state of birth. All regressions include controls for demographics and state-level characteristics, birth state and birth year fixed effects, birth state linear time trends, as well as region-by-birth year and census year-by-birth year fixed effects. Estimates are weighted using Census sample weights, and standard errors are clustered on the state of birth. The sample consists of individuals born between 1880 and 1930, and that are at least 20 years old at the time of observation. We exclude states that passed suffrage prior to 1900. Source: 1940-1960 decennial censuses. ${ }^{*} \mathrm{p}<0.10,{ }^{* *} \mathrm{p}<0.05,{ }^{* * *} \mathrm{p}<0.01$. 
Table 4: Effect of Suffrage on Years of Education Differential Effects by Region

\begin{tabular}{|c|c|c|c|c|c|c|c|c|}
\hline & \multicolumn{4}{|c|}{ Keep Region: } & \multicolumn{4}{|c|}{ Drop Region: } \\
\hline & $\mathrm{NE}$ & MW & $\mathrm{S}$ & $\mathrm{W}$ & $\mathrm{NE}$ & MW & $\mathrm{S}$ & $\mathrm{W}$ \\
\hline \multicolumn{9}{|l|}{ A: Whites } \\
\hline Suff Share 0-15 & $\begin{array}{l}0.339^{* *} \\
(0.145)\end{array}$ & $\begin{array}{l}-0.271 \\
(0.228) \\
\end{array}$ & $\begin{array}{l}1.045^{* *} \\
(0.448)\end{array}$ & $\begin{array}{l}-0.234 \\
(0.278)\end{array}$ & $\begin{array}{c}0.016 \\
(0.204) \\
\end{array}$ & $\begin{array}{l}0.486^{* *} \\
(0.215) \\
\end{array}$ & $\begin{array}{l}-0.147 \\
(0.217)\end{array}$ & $\begin{array}{c}0.024 \\
(0.212) \\
\end{array}$ \\
\hline Mean Y & 10.299 & 10.239 & 9.117 & 11.021 & 9.822 & 9.793 & 10.317 & 9.904 \\
\hline Observations & 397080 & 509551 & 421211 & 66013 & 996775 & 884304 & 972644 & 1327842 \\
\hline \multicolumn{9}{|l|}{ B: Blacks } \\
\hline Suff Share 0-15 & $\begin{array}{l}2.654^{* *} \\
(1.112)\end{array}$ & $\begin{array}{c}1.168^{* * *} \\
(0.363)\end{array}$ & $\begin{array}{l}1.195^{* *} \\
(0.470)\end{array}$ & $\begin{array}{l}13.375 \\
(9.836)\end{array}$ & $\begin{array}{c}1.110^{* * *} \\
(0.278)\end{array}$ & $\begin{array}{c}1.300^{* * *} \\
(0.431)\end{array}$ & $\begin{array}{c}1.216^{* * *} \\
(0.316)\end{array}$ & $\begin{array}{c}1.031^{* * *} \\
(0.250)\end{array}$ \\
\hline Mean Y & 9.406 & 9.414 & 6.446 & 10.384 & 6.626 & 6.610 & 9.443 & 6.746 \\
\hline Observations & 7381 & 8128 & 140982 & 537 & 149647 & 148900 & 16046 & 156491 \\
\hline RegionxBY FE & & & & & Yes & Yes & Yes & Yes \\
\hline
\end{tabular}

Notes: This table contains results obtained when the dependent variable is years of education and the main independent variable is suffrage exposure, which is defined as the share of time between birth and age 15 that an individual was exposed to a suffrage law in his state of birth. In each regression, we either restrict the analysis to one region or show the results dropping one region, indicated in the column header. Regions are abbreviated as follows: "S" for South, "W" for West, "MW" for Midwest, and "NE" for Northeast. All regressions include controls for demographics and state-level characteristics, birth state and birth year fixed effects, birth state linear time trends, as well as region-by-birth year and census year-by-birth year fixed effects. Estimates are weighted using Census sample weights, and standard errors are clustered on the state of birth. The sample consists of individuals born between 1880 and 1930, and that are at least 20 years old at the time of observation. We exclude states that passed suffrage prior to 1900. Source: 1940-1960 decennial censuses. * $\mathrm{p}<0.10,{ }^{* *} \mathrm{p}<0.05, * * * \mathrm{p}<0.01$.

Table 5: Effect of Suffrage on Years of Education Interaction with Pre-treatment Education Levels

\begin{tabular}{|c|c|c|c|c|c|}
\hline & \multirow[b]{2}{*}{ All } & \multicolumn{2}{|c|}{ Whites } & \multicolumn{2}{|c|}{ Blacks } \\
\hline & & Males & Females & Males & Females \\
\hline Suff Share 0-15 & $\begin{array}{l}1.234^{* *} \\
(0.568)\end{array}$ & $\begin{array}{c}2.400^{* * *} \\
(0.742)\end{array}$ & $\begin{array}{c}3.032^{* * *} \\
(0.595)\end{array}$ & $\begin{array}{l}3.079^{* *} \\
(1.474)\end{array}$ & $\begin{array}{c}3.506^{* * *} \\
(1.160)\end{array}$ \\
\hline Suff Share 0-15 x Pre-Period Education & $\begin{array}{c}-0.128^{* *} \\
(0.058)\end{array}$ & $\begin{array}{c}-0.269^{* * *} \\
(0.084)\end{array}$ & $\begin{array}{c}-0.323^{* * *} \\
(0.059)\end{array}$ & $\begin{array}{l}-0.281 \\
(0.189)\end{array}$ & $\begin{array}{c}-0.394^{* *} \\
(0.172)\end{array}$ \\
\hline Mean Education & 9.634 & 9.840 & 10.072 & 6.351 & 7.125 \\
\hline Observations & 1555424 & 688363 & 705492 & 74346 & 82655 \\
\hline
\end{tabular}

Notes: This table contains results obtained when the dependent variable is years of education and the main independent variable is suffrage exposure, which is defined as the share of time between birth and age 15 that an individual was exposed to a suffrage law in his state of birth. Moreover, we include interactions between suffrage exposure and pre-treatment education levels, calculated as the average education for individuals age 16 and above in the year that suffrage was passed in demographic cells defined by gender, race, and state. All regressions include controls for demographics and state-level characteristics, birth state and birth year fixed effects, birth state linear time trends, as well as region-by-birth year and census year-by-birth year fixed effects. Estimates are weighted using Census sample weights, and standard errors are clustered on the state of birth. The sample consists of individuals born between 1880 and 1930, and that are at least 20 years old at the time of observation. We exclude states that passed suffrage prior to 1900. Source: 1940-1960 decennial censuses. ${ }^{*} \mathrm{p}<0.10,{ }^{* *} \mathrm{p}<0.05,{ }^{* * *} \mathrm{p}<0.01$. 


\section{Table 6: Effect of Suffrage on Years of Education - Mandatory vs Not Mandatory States}

\begin{tabular}{lccc}
\hline \hline & All & Whites & Blacks \\
\hline Suff Share 0-15 & 0.045 & 0.015 & $0.886^{* * *}$ \\
& $(0.215)$ & $(0.204)$ & $(0.286)$ \\
& & & \\
Suff Share 0-15 x Mandatory States & $0.268^{* *}$ & 0.132 & $0.505^{* *}$ \\
& $(0.116)$ & $(0.127)$ & $(0.236)$ \\
\hline Mean Education & 9.634 & 9.958 & 6.759 \\
Observations & 1555475 & 1393855 & 157028 \\
\hline \hline
\end{tabular}

Notes: This table contains results obtained when the dependent variable is years of education and the main independent variable is suffrage exposure, which is defined as the share of time between birth and age 15 that an individual was exposed to a suffrage law in his state of birth. Suffrage exposure is interacted with indicators for "mandatory" and voluntary states, where "mandatory states" are the state that did not pass suffrage prior to the Nineteenth Amendment nor voluntarily ratified it. All regressions include controls for demographics and state-level characteristics, birth state and birth year fixed effects, birth state linear time trends, as well as region-by-birth year and census year-by-birth year fixed effects. Estimates are weighted using Census sample weights, and standard errors are clustered on the state of birth. The sample consists of individuals born between 1880 and 1930, and that are at least 20 years old at the time of observation. We exclude states that passed suffrage prior to 1900. Source: 1940-1960 decennial censuses. ${ }^{*} \mathrm{p}<0.10,{ }^{* *} \mathrm{p}<0.05,{ }^{* * *} \mathrm{p}<0.01$.

Table 7: Effect of Suffrage on Years of Education - Check for Migration

\begin{tabular}{|c|c|c|c|c|c|c|}
\hline & \multicolumn{3}{|c|}{ Whites } & \multicolumn{3}{|c|}{ Blacks } \\
\hline & All & Non Movers & Movers & All & Non Movers & Movers \\
\hline \multirow[t]{2}{*}{ Suff Share 0-15 } & 0.027 & -0.033 & 0.137 & $1.067^{* * *}$ & $1.619^{* * *}$ & 0.434 \\
\hline & $(0.204)$ & $(0.228)$ & $(0.150)$ & $(0.251)$ & $(0.351)$ & $(0.451)$ \\
\hline Mean Education & 9.958 & 9.724 & 10.445 & 6.759 & 6.257 & 7.454 \\
\hline Observations & 1393855 & 949891 & 443964 & 157028 & 92760 & 64268 \\
\hline
\end{tabular}

Notes: This table contains results obtained when the dependent variable is years of education and the main independent variable is suffrage exposure, which is defined as the share of time between birth and age 15 that an individual was exposed to a suffrage law in his state of birth. All regressions include controls for demographics and state-level characteristics, birth state and birth year fixed effects, birth state linear time trends, as well as region-by-birth year and census year-by-birth year fixed effects. Estimates are weighted using Census sample weights, and standard errors are clustered on the state of birth. The sample consists of individuals born between 1880 and 1930, and that are at least 20 years old at the time of observation. We exclude states that passed suffrage prior to 1900 . Source: 1940-1960 decennial censuses. ${ }^{*} \mathrm{p}<0.10,{ }^{* *} \mathrm{p}<0.05,{ }^{* * *} \mathrm{p}<0.01$. 


\section{$10 \quad$ Figures}

Figure 1: Timing of Suffrage Laws

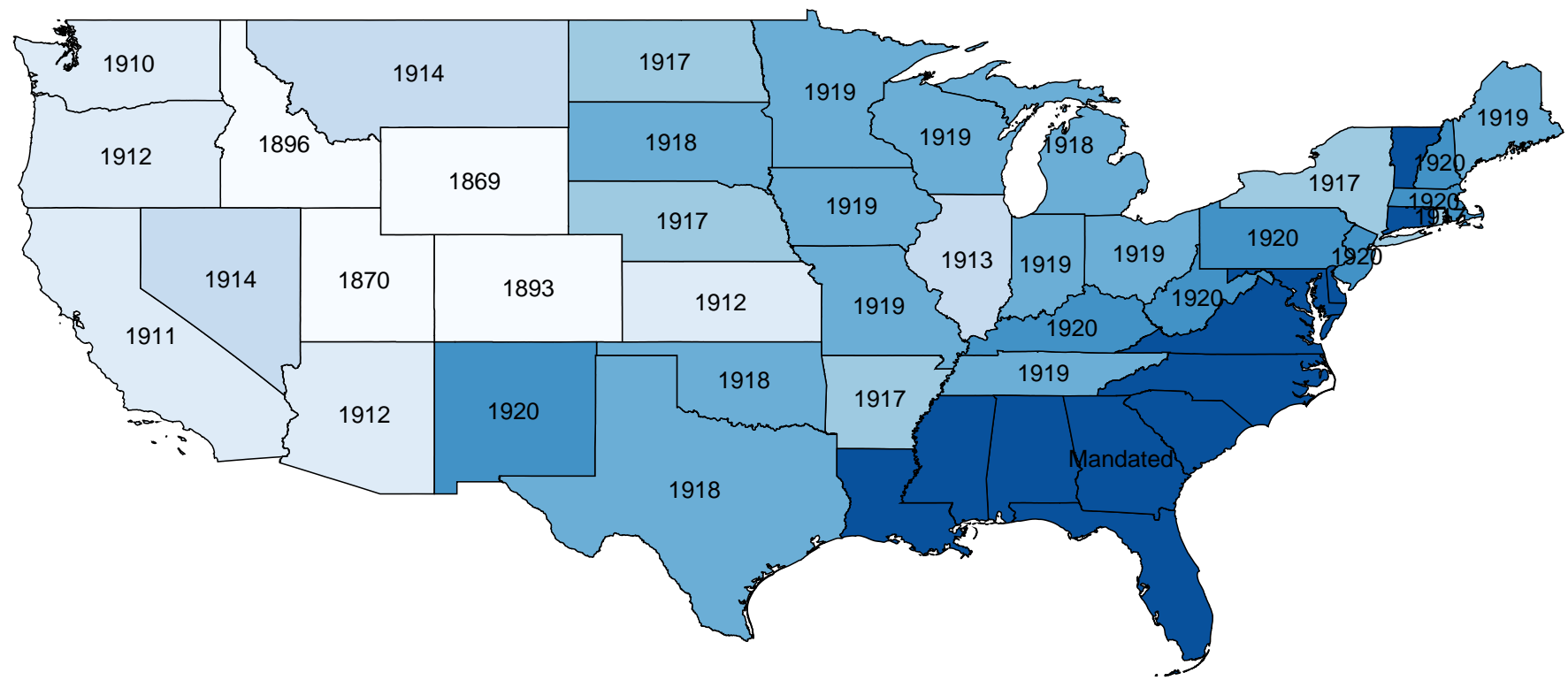

Notes: Suffrage laws are from Lott and Kenny (1999) and Miller (2008). Years are for the first suffrage law in the state. "Mandatory states" implemented suffrage as a result of the Nineteenth Amendment, in 1920. See text for further detail. 
Figure 2: Effect of Suffrage on Presidential Turnout

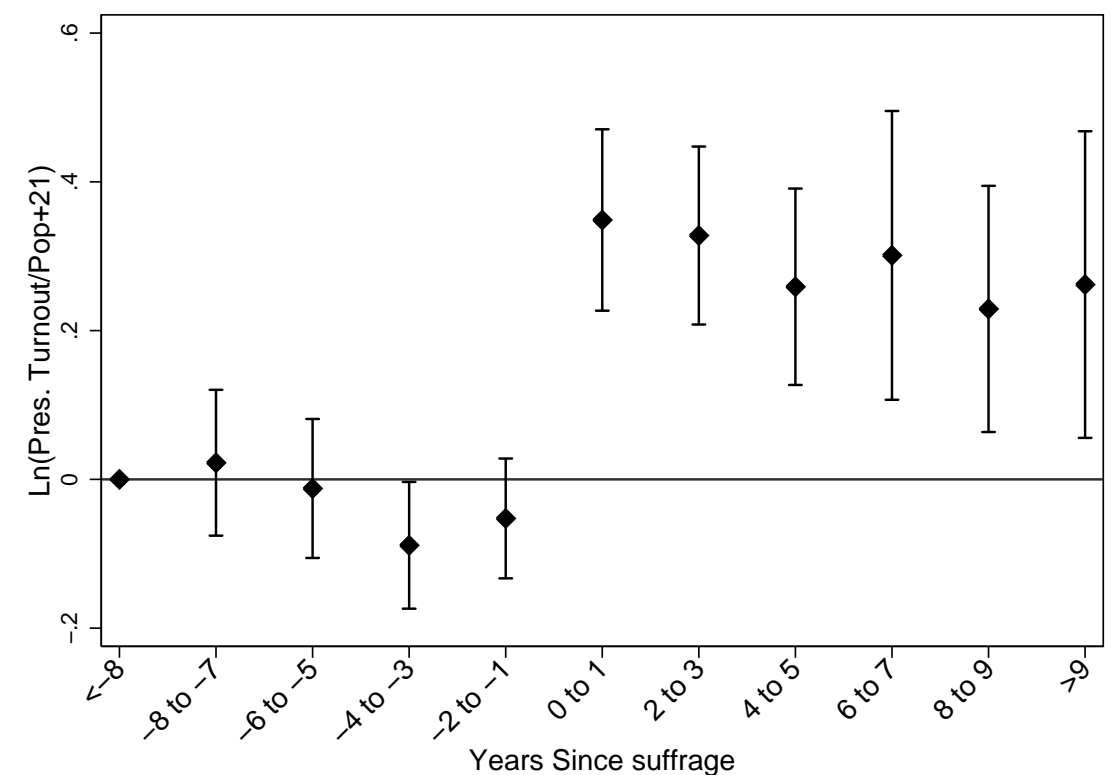

Notes: This figure plots the estimated coefficients obtained from an event study specification that analyzes the effect of suffrage on state-level presidential turnout, defined as the natural logarithm of total number of votes at the presidential elections divided by the voting eligible age, $21+$. The specification includes state and year fixed effects, state linear time trends, region-by-year fixed effects, and state controls such as percentage white, percentage female, percentage urban, percentage literate, population, farm value, employment, and wages. Years since suffrage -8 and earlier is the omitted category so estimates are relative to that point. Estimates are weighted using population weights, and standard errors are clustered at the state level. The sample excludes states that passed suffrage prior to 1900. Sources: Turnout: "Electoral Data for Counties in the United States: Presidential and Congressional Races, 1840-1972" (ICPSR 8611); Population: 1900-1930 censuses. 
Figure 3: Variation in Age of First Exposure to Suffrage Among the 1880-1930 Cohorts, by Suffrage Year

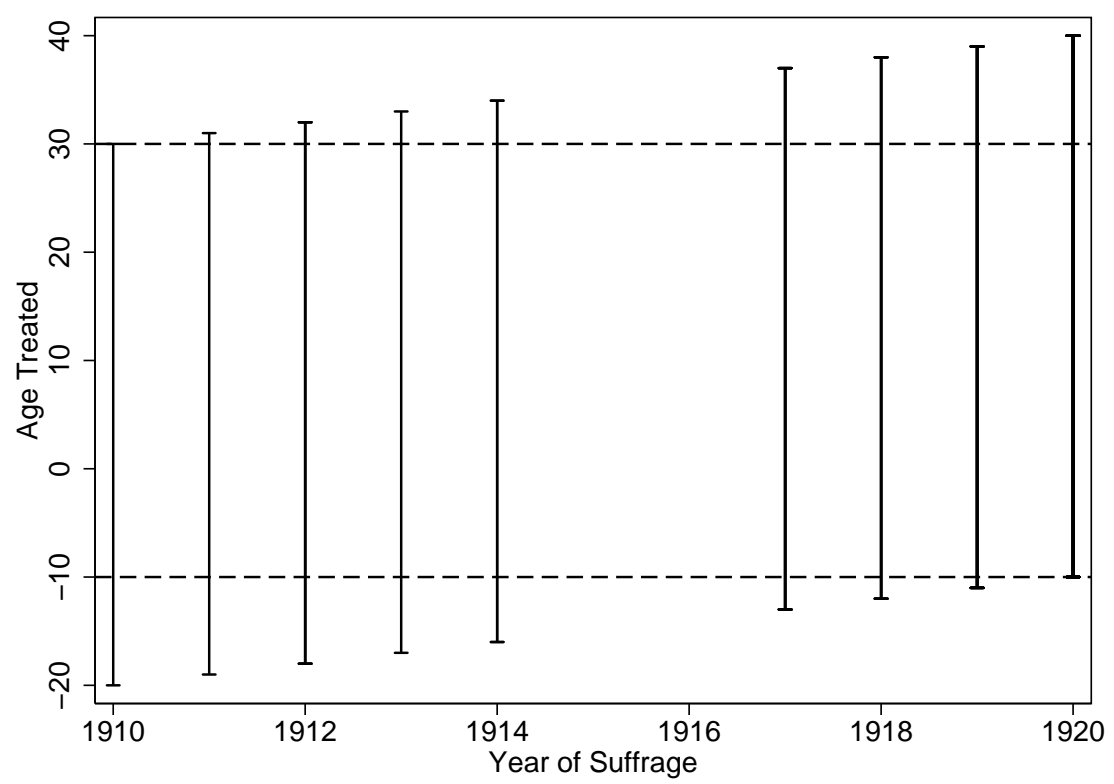

Notes: This figure presents the amount of variation in age of first treatment in the sample by the year in which suffrage was passed in the state. The sample consists of individuals born between 1880 and 1930, and that are at least 20 years old at the time of observation. We exclude states that passed suffrage prior to 1900. Source: 1940-1960 decennial censuses. 
Figure 4: Variation in Exposure to Suffrage, by Cohort

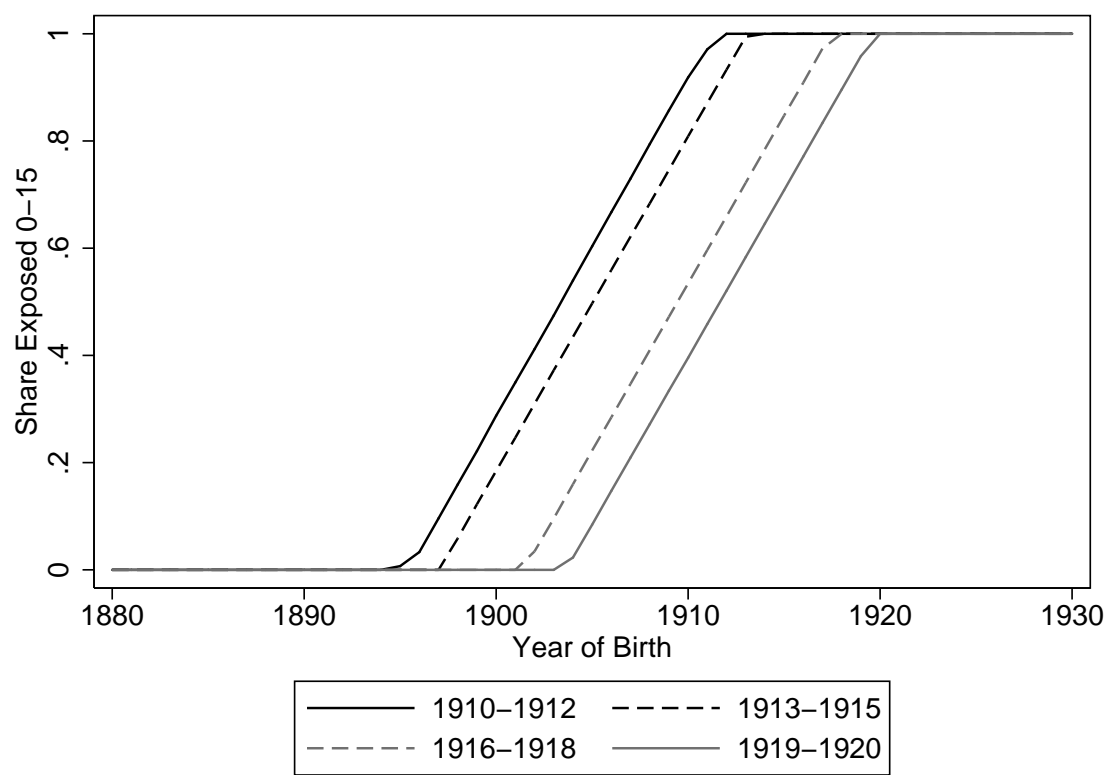

Notes: This figure presents the amount of variation in suffrage exposure in the sample, by cohort. We plot this variation separately for four groups, which enacted suffrage laws between the period 1910-1912, 1913-1915, 1916-1918, and 1919-1920 respectively. "Percent Exposed 0-15" is defined as the share of time between birth and age 15 that an individual was exposed to a suffrage law in his state of birth. The sample consists of individuals born between 1880 and 1930, and that are at least 20 years old at the time of observation. We exclude states that passed suffrage prior to 1900. Source: 1940-1960 decennial censuses. 


\section{Figure 5: Effect of Suffrage at Each Age of First Exposure on Years of Education, By Race}

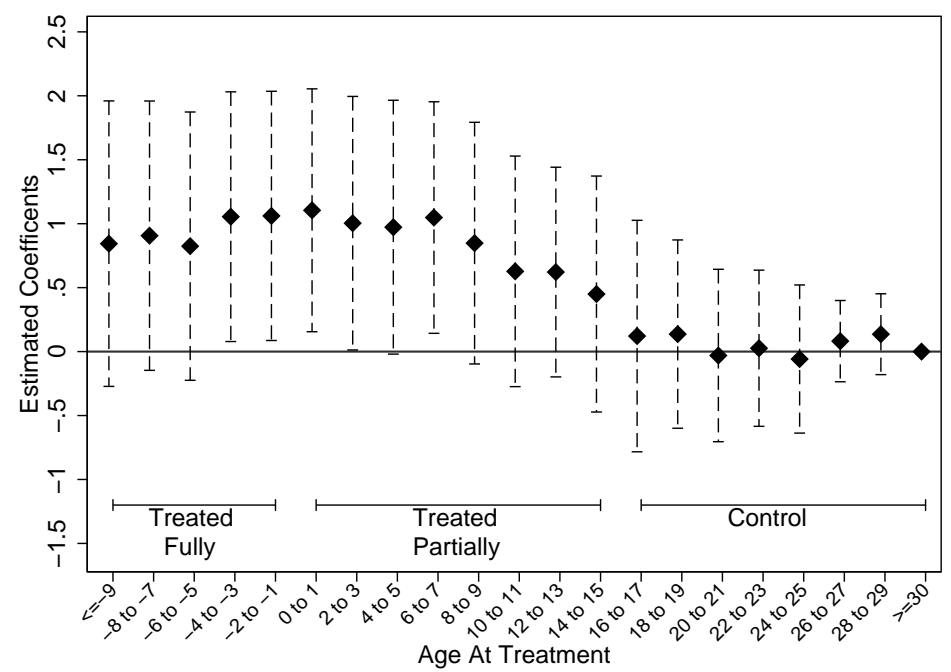

(a) Blacks

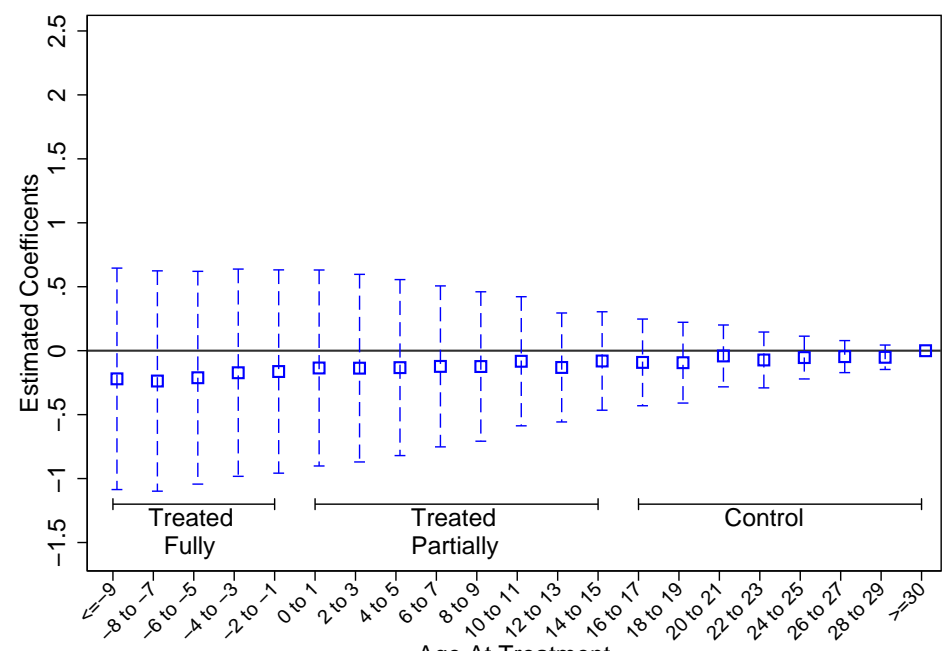

Age At Treatment

(b) Whites

Notes: This figure plots the estimated coefficients (and 95\% confidence intervals) obtained from event study specifications that analyze the effect of suffrage at each age of first exposure on educational attainment, estimated separately for whites and blacks. All specifications include controls for demographics and state-level characteristics, birth state and birth year fixed effects, birth state linear time trends, as well as region-by-birth year and census year-by-birth year fixed effects. Age at treatment $\geq 30$ is the omitted category so estimates are relative to that point. Estimates are weighted using Census sample weights, and standard errors are clustered on the state of birth. The sample consists of individuals born between 1880 and 1930, and that are at least 20 years old at the time of observation. We exclude states that passed suffrage prior to 1900. Source: 1940-1960 decennial censuses. 
Figure 6: Subgroup Averages of Pre-Treatment Education and the Estimated Effects of Suffrage on Years of Education

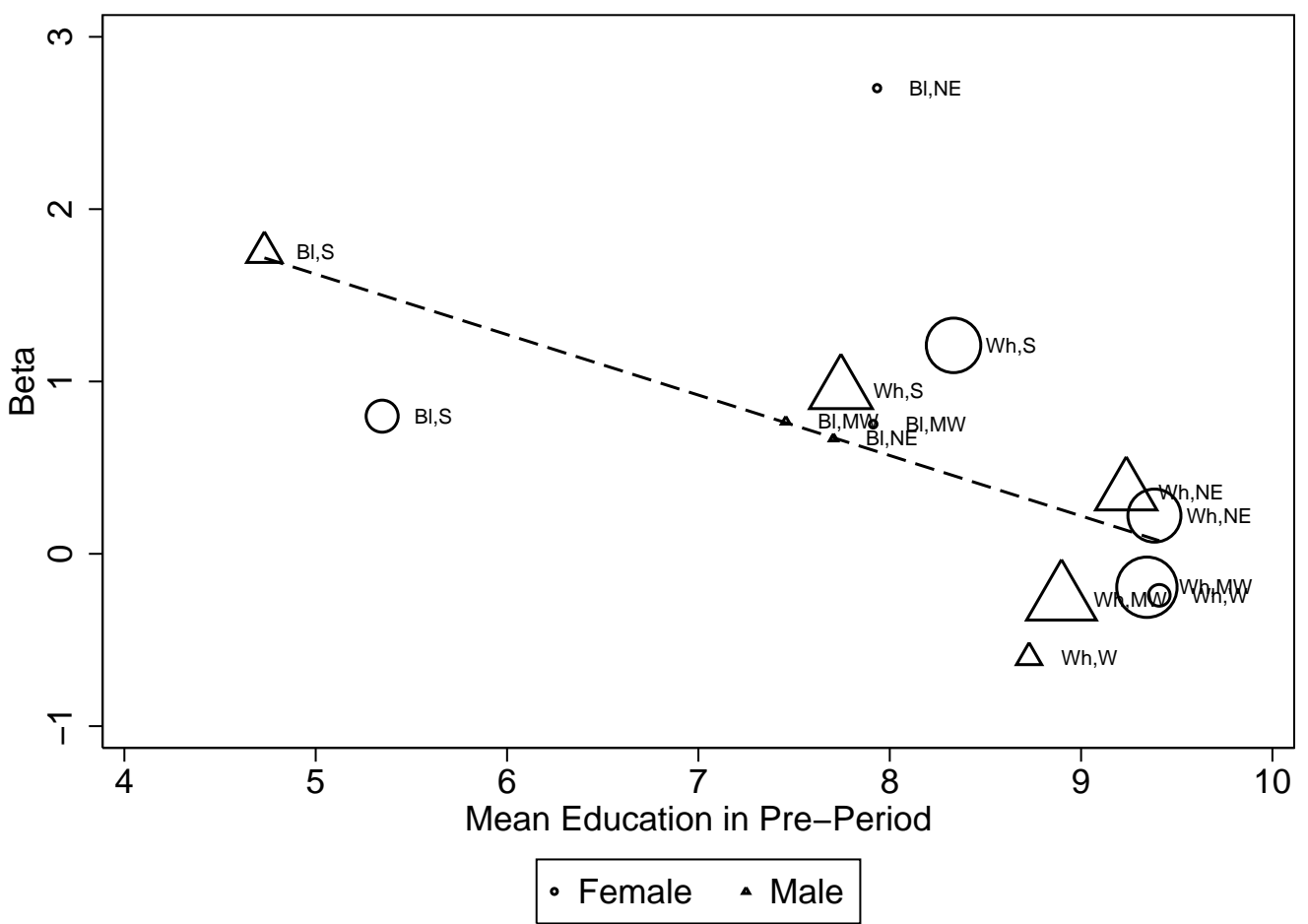

Notes: To create this figure, we first estimate specifications that analyze the effect of suffrage exposure on educational attainment separately for demographic groups defined according to region of birth, race and gender. We then plot the estimated coefficients along with the average pre-treatment educational attainment (average attainment among individuals that were age 16 or older by the passage of suffrage in the state) for each demographic group. Regions are abbreviated as follows: "S" for South, "W" for West, "MW" for Midwest, and "NE" for Northeast, and race is abbreviated as: "Bl" for black and "Wh" for white. We do not show blacks in the West due to their small sample size, but an equivalent figure that includes all groups is available on request. All regressions include controls for demographics and state-level characteristics, birth state and birth year fixed effects, birth state linear time trends, as well as region-by-birth year and census year-by-birth year fixed effects. Estimates are weighted using Census sample weights, and standard errors are clustered on the state of birth. The sample consists of individuals born between 1880 and 1930, and that are at least 20 years old at the time of observation. We exclude states that passed suffrage prior to 1900. Source: 1940-1960 decennial censuses. 
Figure 7: Effect of Suffrage on the Distribution of Years of Education, By Race

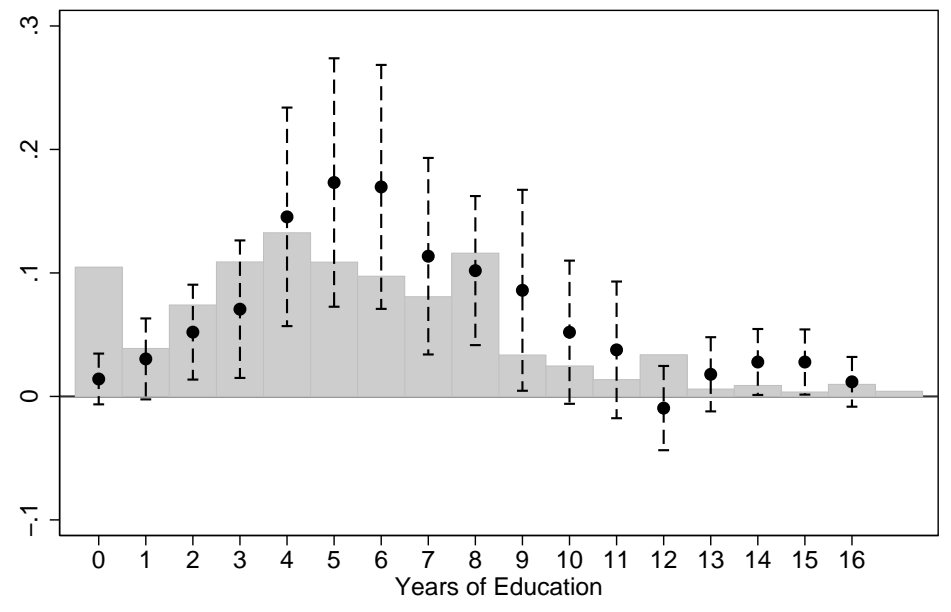

Fraction, at baseline $\bullet$ Estimated Coefficents

(a) Blacks

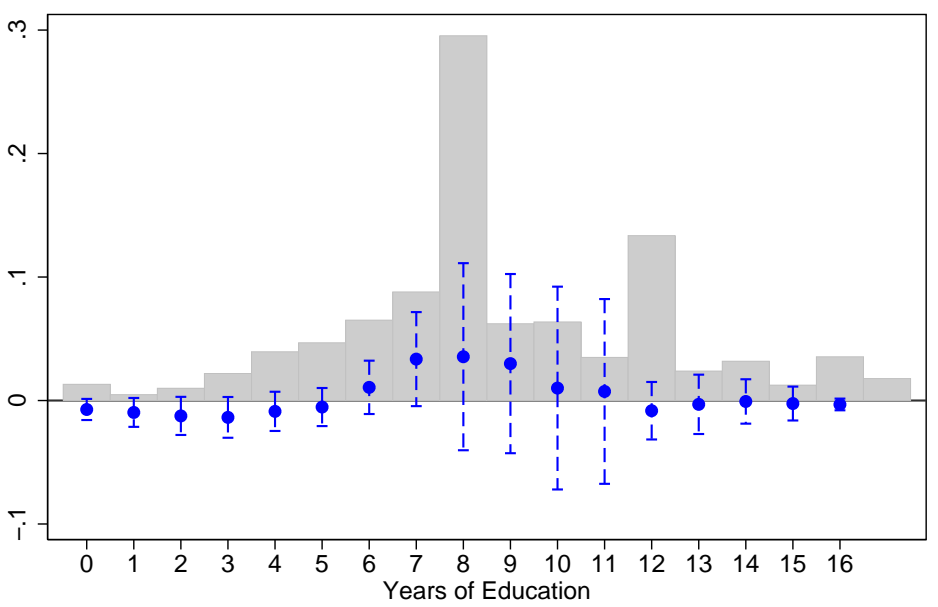

Fraction, at baseline $\quad$ Estimated Coefficents

(b) Whites

Notes: These figures plot the estimated coefficients (and 95\% confidence intervals) obtained from specifications that analyze the effect of suffrage exposure on the likelihood that an individual completes $x$ or greater years of education (1-CDF), where $x$ is represented on the x-axis. All specifications are estimated separately for white and blacks, and they include controls for demographics and state-level characteristics, birth state and birth year fixed effects, birth state linear time trends, as well as region-by-birth year and census year-by-birth year fixed effects. Estimates are weighted using Census sample weights, and standard errors are clustered on the state of birth. The graph also contains a histogram for the share of the "untreated" population - for whom the share of time between birth and age 15 that an individual was exposed to a suffrage law in his state of birth is zero - that has each discrete level of education. The sample consists of individuals born between 1880 and 1930, and that are at least 20 years old at the time of observation. We exclude states that passed suffrage prior to 1900. Source: 1940-1960 decennial censuses. 


\section{Figure 8: Effect of Suffrage at Each Age of First Exposure on Literacy, By Race}

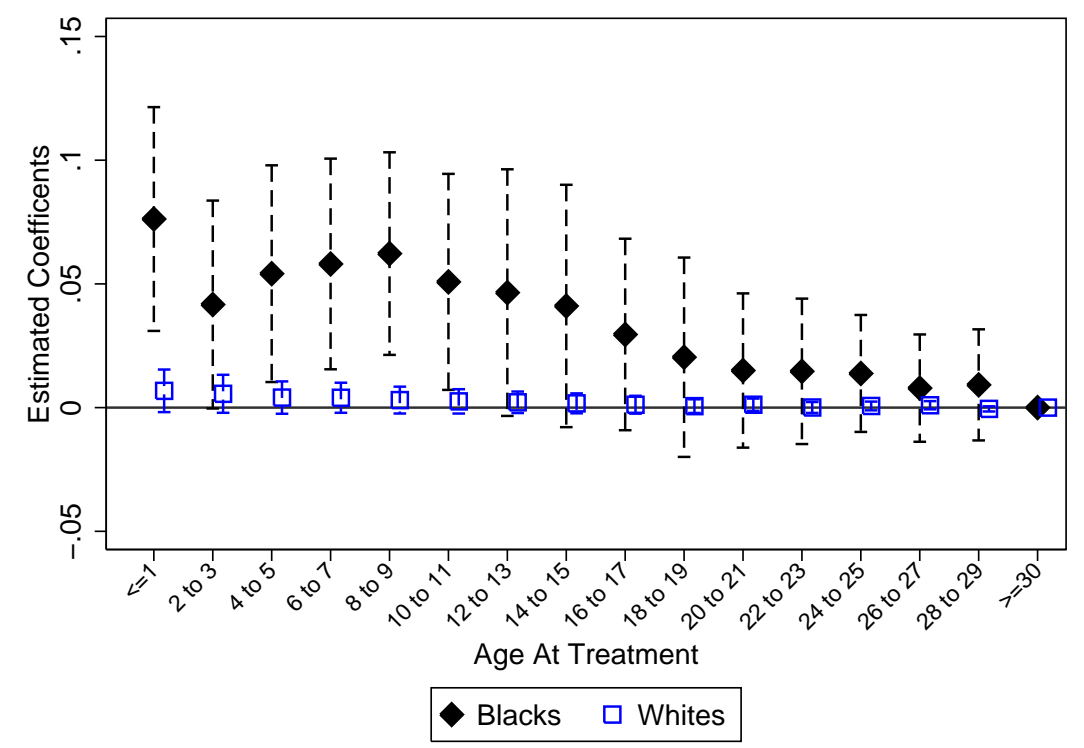

Notes: This figure plots the estimated coefficients (and 95\% confidence intervals) obtained from event study specifications that analyze the effect of suffrage at each age of first exposure on literacy attainment, separately for whites and blacks. All specifications include controls for demographics and state-level characteristics, birth state and birth year fixed effects, birth state linear time trends, as well as region-by-birth year and census year-by-birth year fixed effects. Age at treatment $\geq 30$ is the omitted category so estimates are relative to that point. Estimates are weighted using Census sample weights, and standard errors are clustered on the state of birth. The sample consists of individuals born between 1880 and 1915, and that are at least 15 years old at the time of observation. We exclude states that passed suffrage prior to 1900. Source: 1920-1930 decennial censuses. 
Figure 9: Effect of Suffrage at Each Age of First Exposure on Labor Market Outcomes, By Race and South/Non-South

(a) Likelihood of Positive Income

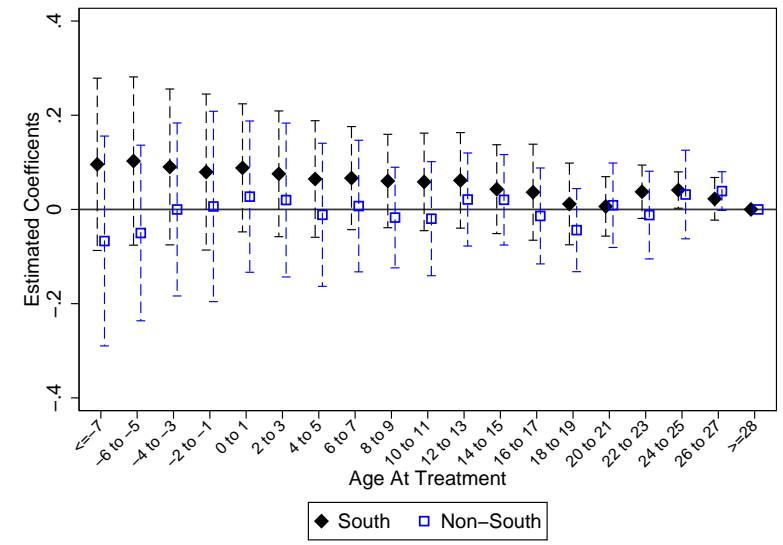

(i) Blacks

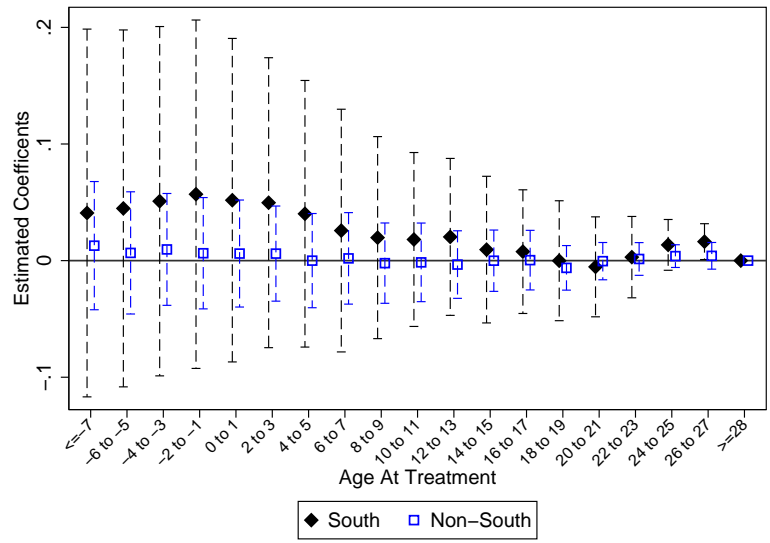

(ii) Whites

(b) Log Income

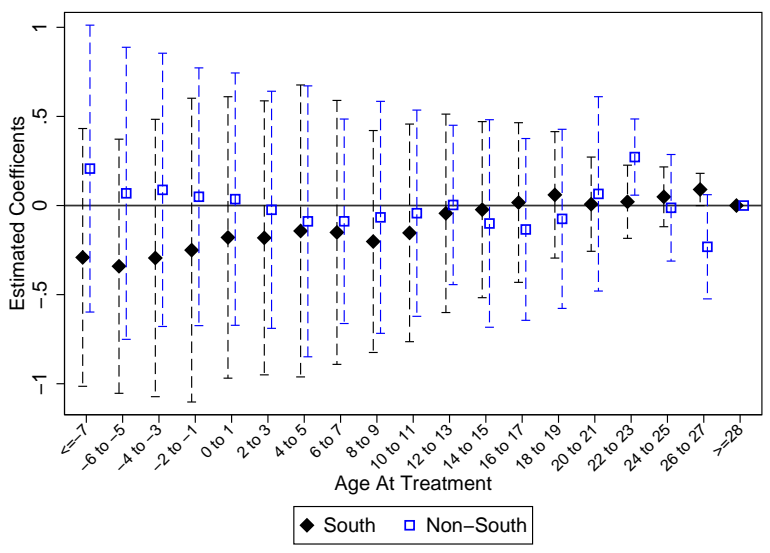

(i) Blacks

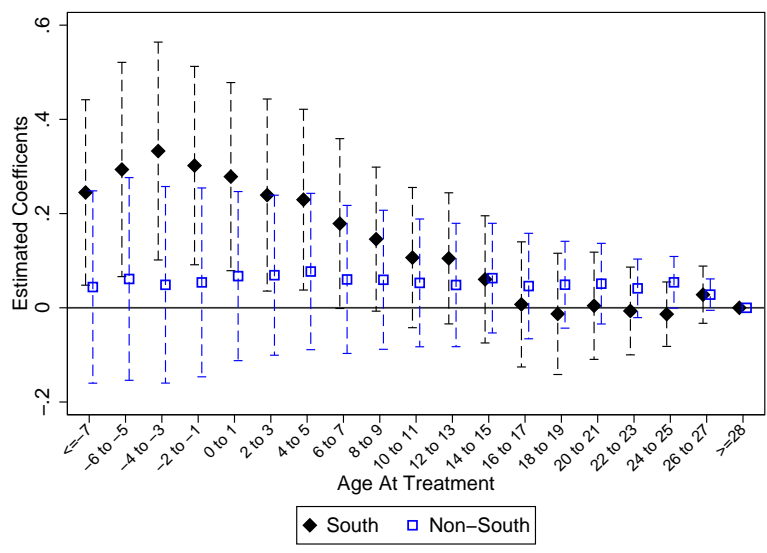

(ii) Whites

Notes: This figure plots the estimated coefficients (and 95\% confidence intervals) obtained from event study specifications that analyze the effect of suffrage at each age of first exposure on labor market outcomes, and includes an interaction between the age at treatment dummies and whether the state of birth is in the South or Non-South, estimated separately for whites and blacks. All specifications include controls for demographics and state-level characteristics, birth state and birth year fixed effects, birth state linear time trends, as well as region-by-birth year and census year-by-birth year fixed effects. Age at treatment $\geq 30$ is the omitted category so estimates are relative to that point. Estimates are weighted using Census sample weights, and standard errors are clustered on the state of birth. The sample consists of individuals born between 1880 and 1930 , and that are at between 30 and 60 years old at the time of observation. We exclude states that passed suffrage prior to 1900. Source: 1940-1960 decennial censuses. 


\section{A Appendix: Further Results}

Table A.1: Effect of Suffrage on Years of Education Effects Beyond Age 15

\begin{tabular}{lccc}
\hline \hline & All & Whites & Blacks \\
\hline Suff Share 0-15 & 0.091 & 0.035 & $1.183^{* * *}$ \\
& $(0.251)$ & $(0.240)$ & $(0.286)$ \\
Suff Share 16-22 & 0.018 & 0.001 & 0.278 \\
& $(0.086)$ & $(0.082)$ & $(0.314)$ \\
& & & \\
Suff Share 23-30 & -0.040 & -0.044 & -0.220 \\
& $(0.109)$ & $(0.107)$ & $(0.446)$ \\
\hline Mean Education & 9.634 & 9.958 & 6.759 \\
R-Squared & 0.197 & 0.126 & 0.219 \\
Observations & 1555475 & 1393855 & 157028 \\
\hline \hline
\end{tabular}

Notes: This table contains results obtained when the dependent variable is years of education and the main independent variables are "Suff Share $\mathrm{x}-\mathrm{y}$ ", which are defined as the share of time between ages $\mathrm{x}$ and $\mathrm{y}$ that an individual was exposed to a suffrage law in his state of birth. All regressions include controls for demographics and state-level characteristics, birth state and birth year fixed effects, birth state linear time trends, as well as region-by-birth year and census year-by-birth year fixed effects. The state controls include percentage white, percentage female, percentage urban, percentage literate, population, farm value, employment, and wages, as well as controls for compulsory schooling laws and the Rosenwald school initiative. All regressions include sample weights, and standard errors are clustered at the state level. The sample consists of individuals born between 1880 and 1930, and that are at least 20 years old at the time of observation. We exclude states that passed suffrage prior to 1900. Source: 1940-1960 decennial censuses. ${ }^{*} \mathrm{p}<0.10,{ }^{* *} \mathrm{p}<0.05,{ }^{* * *} \mathrm{p}<0.01$. 
Table A.2: Effect of Suffrage on Labor Market Outcomes

\begin{tabular}{|c|c|c|c|c|c|c|}
\hline & \multicolumn{3}{|c|}{ Pr(Positive Income) } & \multicolumn{3}{|c|}{ Log Income } \\
\hline & $(1)$ & $(2)$ & (3) & (4) & $(5)$ & $(6)$ \\
\hline \multicolumn{7}{|l|}{ A: All } \\
\hline \multirow[t]{2}{*}{ Suff Share 0-15 } & $0.016^{*}$ & 0.010 & 0.003 & $0.037^{* *}$ & 0.005 & -0.015 \\
\hline & $(0.009)$ & $(0.007)$ & $(0.005)$ & $(0.017)$ & $(0.027)$ & $(0.023)$ \\
\hline \multirow[t]{2}{*}{ Suff Share $0-15 *$ South } & & & 0.058 & & & 0.160 \\
\hline & & & $(0.043)$ & & & $(0.105)$ \\
\hline Mean Y & 0.666 & 0.666 & 0.666 & 8.501 & 8.501 & 8.501 \\
\hline Observations & 1540857 & 1540857 & 1540857 & 1054320 & 1054320 & 1054320 \\
\hline \multicolumn{7}{|l|}{ B: Whites } \\
\hline \multirow[t]{2}{*}{$\overline{\text { Suff Share } 0-15}$} & 0.013 & 0.010 & 0.005 & $0.051^{* * *}$ & 0.021 & -0.010 \\
\hline & $(0.008)$ & $(0.007)$ & $(0.006)$ & $(0.016)$ & $(0.027)$ & $(0.022)$ \\
\hline \multirow[t]{2}{*}{ Suff Share 0-15* South } & & & 0.055 & & & $0.308^{* * *}$ \\
\hline & & & $(0.044)$ & & & $(0.090)$ \\
\hline Mean Y & 0.661 & 0.661 & 0.661 & 8.570 & 8.570 & 8.570 \\
\hline Observations & 1373500 & 1373500 & 1373500 & 930553 & 930553 & 930553 \\
\hline \multicolumn{7}{|l|}{ C:Blacks } \\
\hline \multirow[t]{2}{*}{$\overline{\text { Suff Share } 0-15}$} & 0.038 & 0.044 & $0.102^{* *}$ & -0.026 & -0.013 & 0.041 \\
\hline & $(0.044)$ & $(0.046)$ & $(0.041)$ & $(0.119)$ & $(0.121)$ & $(0.135)$ \\
\hline \multirow[t]{2}{*}{ Suff Share 0-15* South } & & & -0.101 & & & -0.094 \\
\hline & & & $(0.063)$ & & & $(0.217)$ \\
\hline Mean Y & 0.718 & 0.718 & 0.718 & 7.944 & 7.944 & 7.944 \\
\hline Observations & 162671 & 162671 & 162671 & 120704 & 120704 & 120704 \\
\hline RegionxBY FE & & Yes & Yes & & Yes & Yes \\
\hline
\end{tabular}

Notes: This table contains results obtained when the dependent variables are the labor market outcomes in each panel title, and the independent variable is suffrage exposure, which is defined as the share of time between birth and age 15 that an individual was exposed to a suffrage law in his state of birth. All regressions include controls for demographics and state-level characteristics, birth state and birth year fixed effects, birth state linear time trends, as well as region-by-birth year and census year-by-birth year fixed effects. Estimates are weighted using Census sample weights, and standard errors are clustered on the state of birth. The sample consists of individuals born between 1880 and 1930, and that are at between 30 and 60 years old at the time of observation. We exclude states that passed suffrage prior to 1900. Source: 1940-1960 decennial censuses. ${ }^{*} \mathrm{p}<0.10,{ }^{* *} \mathrm{p}<0.05,{ }^{* * *} \mathrm{p}<0.01$. 
Table A.3: Effect of Suffrage on Mortality

\begin{tabular}{|c|c|c|c|c|}
\hline & $(1)$ & $(2)$ & $(3)$ & $(4)$ \\
\hline \multicolumn{5}{|l|}{ A: All } \\
\hline Post Suffrage & $\begin{array}{c}-0.120^{* * *} \\
(0.031)\end{array}$ & $\begin{array}{c}-0.095^{* * *} \\
(0.030)\end{array}$ & $\begin{array}{l}-0.010 \\
(0.024)\end{array}$ & $\begin{array}{l}-0.003 \\
(0.025)\end{array}$ \\
\hline Post Suffrage $*$ South & & $\begin{array}{c}-0.174^{* * *} \\
(0.030)\end{array}$ & & $\begin{array}{c}-0.087^{* *} \\
(0.040)\end{array}$ \\
\hline Mean Y & 7.210 & 7.210 & 7.210 & 7.210 \\
\hline Observations & 2536 & 2536 & 2536 & 2536 \\
\hline \multicolumn{5}{|l|}{ B: Whites } \\
\hline Post Suffrage & $\begin{array}{c}-0.139^{* * *} \\
(0.032)\end{array}$ & $\begin{array}{c}-0.112^{* * *} \\
(0.031)\end{array}$ & $\begin{array}{l}-0.014 \\
(0.023)\end{array}$ & $\begin{array}{l}-0.006 \\
(0.024)\end{array}$ \\
\hline Post Suffrage $*$ South & & $\begin{array}{c}-0.170^{* * *} \\
(0.030)\end{array}$ & & $\begin{array}{c}-0.088^{* *} \\
(0.035)\end{array}$ \\
\hline Mean Y & 7.000 & 7.000 & 7.000 & 7.000 \\
\hline Observations & 2429 & 2429 & 2429 & 2429 \\
\hline \multicolumn{5}{|l|}{$\underline{C: B l a c k s}$} \\
\hline Post Suffrage & $\begin{array}{c}-0.125^{* *} \\
(0.059)\end{array}$ & $\begin{array}{c}-0.066 \\
(0.065)\end{array}$ & $\begin{array}{l}-0.005 \\
(0.080)\end{array}$ & $\begin{array}{c}0.007 \\
(0.087)\end{array}$ \\
\hline Post Suffrage $*$ South & & $\begin{array}{c}-0.304^{* * *} \\
(0.092) \\
\end{array}$ & & $\begin{array}{l}-0.117 \\
(0.095)\end{array}$ \\
\hline Mean Y & 4.487 & 4.487 & 4.487 & 4.487 \\
\hline Observations & 2103 & 2103 & 2103 & 2103 \\
\hline Region*BY FE & & & Yes & Yes \\
\hline
\end{tabular}

Notes: Post suffrage is a dummy variable takes the value one by the current year. All regressions include controls for state-level characteristics, state and year fixed effects, state linear time trends. Estimates are weighted using population weights, and standard errors are clustered on the state. We exclude states that passed suffrage prior to 1900 . Source: Mortality records by state, age, race, and gender from 1900 to 1932 obtained from the Centers for Disease Control and Prevention. ${ }^{*} \mathrm{p}<0.10,{ }^{* *} \mathrm{p}<0.05,{ }^{* * *} \mathrm{p}<0.01$. 
Table A.4: Impact of Suffrage on Measures of Educational Quality

\begin{tabular}{|c|c|c|c|c|}
\hline & \multicolumn{2}{|c|}{ Pupil Teacher Ratio } & \multicolumn{2}{|c|}{ Term Length } \\
\hline & (1) & (2) & (3) & (4) \\
\hline \multicolumn{5}{|l|}{ A: Post } \\
\hline Post Suffrage & $\begin{array}{l}-0.037 \\
(0.459)\end{array}$ & $\begin{array}{c}0.140 \\
(0.428)\end{array}$ & $\begin{array}{c}0.079 \\
(2.991)\end{array}$ & $\begin{array}{l}-2.374 \\
(3.346)\end{array}$ \\
\hline Post Suffrage $*$ South & & $\begin{array}{l}-0.803 \\
(1.380)\end{array}$ & & $\begin{array}{c}11.414^{* *} \\
(5.361)\end{array}$ \\
\hline Mean Y & 33.684 & 33.684 & 161.115 & 161.115 \\
\hline Observations & 1200 & 1200 & 1258 & 1258 \\
\hline \multicolumn{5}{|l|}{ B: Post and Change in Trend } \\
\hline Post Suffrage & $\begin{array}{l}-0.058 \\
(0.448)\end{array}$ & $\begin{array}{c}0.019 \\
(0.430)\end{array}$ & $\begin{array}{l}-0.067 \\
(2.829)\end{array}$ & $\begin{array}{l}-2.438 \\
(3.145)\end{array}$ \\
\hline Post Suffrage Trend & $\begin{array}{l}-0.050 \\
(0.221)\end{array}$ & $\begin{array}{l}-0.206 \\
(0.221)\end{array}$ & $\begin{array}{l}-0.330 \\
(0.871)\end{array}$ & $\begin{array}{l}-0.205 \\
(0.914)\end{array}$ \\
\hline Post Suffrage $*$ South & & $\begin{array}{l}-0.152 \\
(1.242)\end{array}$ & & $\begin{array}{l}11.011^{*} \\
(6.022)\end{array}$ \\
\hline Post Suffrage Trend $*$ South & & $\begin{array}{l}1.236^{*} \\
(0.709)\end{array}$ & & $\begin{array}{l}-0.672 \\
(3.067)\end{array}$ \\
\hline Mean Y & 33.684 & 33.684 & 161.115 & 161.115 \\
\hline Observations & 1200 & 1200 & 1258 & 1258 \\
\hline
\end{tabular}

Notes: Post suffrage is a dummy variable takes the value one if the state by the current year. Post suffrage trend captures a break in the trend after the suffrage passed in a state. All regressions include controls for demographics and state-level characteristics, state and year fixed effects, state linear time trends, as well as region-by-year fixed effects. Estimates are weighted using population weights, and standard errors are clustered on the state. We exclude states that passed suffrage prior to 1900. Source: Compilation of data from the Biennial Survey of Education and Card and Krueger (1992). ${ }^{*} \mathrm{p}<0.10,{ }^{* *} \mathrm{p}<0.05,{ }^{*} * *$ $\mathrm{p}<0.01$. 
Table A.5: Impact of Suffrage on Measures of Educational Quality by Race in the South

\begin{tabular}{lccc}
\hline \hline & Pupil Teacher Ratio & Term Length & Teacher Salary \\
\hline \hline A: Blacks & & & \\
Post Suffrage & -4.592 & 21.431 & 23.265 \\
& $(2.794)$ & $(14.692)$ & $(68.549)$ \\
\hline Mean Y & 43.924 & 101.430 & 310.542 \\
Observations & 272 & 272 & 272 \\
& & & \\
\hline B: Whites & & & \\
Post Suffrage & $1.099^{*}$ & 24.762 & $135.259^{*}$ \\
& $(0.602)$ & $(17.112)$ & $(76.533)$ \\
\hline Mean Y & 31.805 & 119.229 & 537.304 \\
Observations & 272 & 272 & 272 \\
\hline \hline
\end{tabular}

Notes: Post suffrage is a dummy variable takes the value one if the state by the current year. All regressions include controls for demographics and state-level characteristics, state and year fixed effects, and state linear time trends. Estimates are weighted using population weights, and standard errors are clustered on the state. Quality data by race are available for the Southern states and Missouri starting 1915. We restrict our analysis to the period between 1915 and 1930. Source: The data from Card and Krueger (1992). * $\mathrm{p}<0.10,{ }^{* *} \mathrm{p}<0.05,{ }^{* * *} \mathrm{p}<0.01$. 
Table A.6: Effect of Suffrage on Years of Education Sensitivity to Alternative Controls

\begin{tabular}{lccc}
\hline \hline & At Birth & Cumulative 0-15 & Pre*Birthyear \\
\hline \hline A: All & & & \\
Suff Share 0-15 & 0.100 & 0.207 & 0.035 \\
& $(0.201)$ & $(0.130)$ & $(0.250)$ \\
\hline Mean Education & 9.634 & 9.634 & 9.634 \\
R-Squared & 0.197 & 0.197 & 0.197 \\
Observations & 1555475 & 1555475 & 1555475 \\
& & & \\
\hline B: Blacks & & & \\
Suff Share 0-15 & $1.123^{* * *}$ & $0.882^{* * *}$ & $1.191^{* * *}$ \\
& $(0.274)$ & $(0.228)$ & $(0.323)$ \\
\hline Mean Education & 6.759 & 6.759 & 6.759 \\
R-Squared & 0.219 & 0.219 & 0.219 \\
Observations & 157028 & 157028 & 157028 \\
& & & \\
\hline : Whites & & & \\
Suff Share 0-15 & 0.052 & 0.156 & -0.023 \\
& $(0.193)$ & $(0.136)$ & $(0.233)$ \\
\hline Mean Education & 9.958 & 9.958 & 9.958 \\
R-Squared & 0.126 & 0.126 & 0.126 \\
Observations & 1393855 & 1393855 & 1393855 \\
\hline \hline
\end{tabular}

Notes: This table contains results obtained when the dependent variable is years of education and the main independent variable is suffrage exposure, which is defined as the share of time between birth and age 15 that an individual was exposed to a suffrage law in his state of birth. All regressions include controls for demographics and state-level characteristics, birth state and birth year fixed effects, birth state linear time trends, as well as region-by-birth year and census year-by-birth year fixed effects. Estimates are weighted using Census sample weights, and standard errors are clustered on the state of birth. The sample consists of individuals born between 1880 and 1930, and that are at least 20 years old at the time of observation. We exclude states that passed suffrage prior to 1900. Source: 1940-1960 decennial censuses. ${ }^{*} \mathrm{p}<0.10,{ }^{* *} \mathrm{p}<0.05,{ }^{* * *} \mathrm{p}<0.01$.

Table A.7: Correlation between Timing of Suffrage and WWII Mobilization Rates

\begin{tabular}{lcc}
\hline \hline & $(1)$ & $(2)$ \\
\hline WW2 Mobilization Rate & $-105.914^{* *}$ & -46.278 \\
& $(44.630)$ & $(58.686)$ \\
\hline Observations & 48 & 48 \\
Region FE & No & Yes \\
\hline \hline
\end{tabular}

Notes: This table contains results obtained when the dependent variable is the year that suffrage was approved in each state and the main independent variable is WWII mobilization rates. All regressions include population weights, and standard errors are clustered at the state level. The sample excludes states that passed suffrage prior to 1900 . Suffrage laws are from Lott and Kenny (1999) and Miller (2008). WWII mobilization rates are from Acemoglu et al. (2004). ${ }^{*} \mathrm{p}<0.10,{ }^{* *} \mathrm{p}<0.05,{ }^{* * *}$ $\mathrm{p}<0.01$. 


\section{Table A.8: Effect of Suffrage on Years of Education - Sensitivity to Measure of Exposure}

\begin{tabular}{lccc}
\hline \hline & All & Whites & Blacks \\
\hline Suffrage by 15 & 0.020 & 0.010 & $0.302^{* * *}$ \\
& $(0.022)$ & $(0.022)$ & $(0.054)$ \\
\hline Mean Education & 9.634 & 9.958 & 6.759 \\
Observations & 1555475 & 1393855 & 157028 \\
\hline \hline
\end{tabular}

Notes: This table contains results obtained when the dependent variable is years of education and the main independent variable is suffrage exposure, which is equal to one if an individual is exposed to suffrage in his state of birth at age 15 or younger. All regressions include controls for demographics and state-level characteristics, birth state and birth year fixed effects, birth state linear time trends, as well as region-by-birth year and census year-by-birth year fixed effects. Estimates are weighted using Census sample weights, and standard errors are clustered on the state of birth The sample consists of individuals born between 1880 and 1930, and that are at least 20 years old at the time of observation. We exclude states that passed suffrage prior to 1900. Source: 1940-1960 decennial censuses. ${ }^{*} \mathrm{p}<0.10$, $* * \mathrm{p}<0.05,{ }^{* * *} \mathrm{p}<0.01$.

Table A.9: Effect of Suffrage on Years of Education Sensitivity to Census

\begin{tabular}{lccccc}
\hline \hline & 1940 & 1950 & 1960 & 1950,1940 Pop & 1960,1940 Pop \\
\hline \hline A: Blacks & & & & & \\
Suff Share 0-15 & 0.126 & $1.768^{* * *}$ & $1.484^{* * *}$ & $3.335^{* *}$ & $1.147^{* *}$ \\
& $(0.281)$ & $(0.587)$ & $(0.449)$ & $(1.517)$ & $(0.457)$ \\
\hline Mean Education & 6.009 & 7.000 & 7.272 & 6.417 & 6.502 \\
Observations & 61004 & 22447 & 73577 & 15839 & 50924 \\
\hline B: Whites & & & & & \\
Suff Share 0-15 & 0.098 & 0.322 & -0.090 & 0.351 & -0.056 \\
& $(0.162)$ & $(0.244)$ & $(0.221)$ & $(0.222)$ & $(0.200)$ \\
\hline Mean Education & 9.567 & 10.164 & 10.173 & 9.755 & 9.735 \\
Observations & 509583 & 204510 & 679762 & 148663 & 483804 \\
\hline \hline
\end{tabular}

Notes: This table contains results obtained when the dependent variable is years of education and the main independent variable is suffrage exposure, which is defined as the share of time between birth and age 15 that an individual was exposed to a suffrage law in his state of birth. All regressions include controls for demographics and state-level characteristics, birth state and birth year fixed effects, birth state linear time trends, as well as region-by-birth year and census year-by-birth year fixed effects. Estimates are weighted using Census sample weights, and standard errors are clustered on the state of birth. The sample consists of individuals born between 1880 and 1930, and that are at least 20 years old at the time of observation. We exclude states that passed suffrage prior to 1900. Source: 1940-1960 decennial censuses. ${ }^{*} \mathrm{p}<0.10,{ }^{* *} \mathrm{p}<0.05,{ }^{* * *} \mathrm{p}<0.01$. 
Table A.10: Effect of Suffrage on Years of Education - Additional Sensitivity Checks

\begin{tabular}{|c|c|c|c|c|c|c|c|}
\hline & \multirow[b]{2}{*}{ All } & \multirow[b]{2}{*}{ Whites } & \multirow[b]{2}{*}{ Blacks } & \multicolumn{2}{|c|}{ Whites } & \multicolumn{2}{|c|}{ Blacks } \\
\hline & & & & Males & Females & Males & Females \\
\hline \multicolumn{8}{|l|}{ A: Include Trend in Pre-Education } \\
\hline Percent of 0-15 Treated & $\begin{array}{c}0.071 \\
(0.216) \\
\end{array}$ & $\begin{array}{c}0.025 \\
(0.204) \\
\end{array}$ & $\begin{array}{c}1.058^{* * *} \\
(0.246)\end{array}$ & $\begin{array}{c}0.006 \\
(0.193)\end{array}$ & $\begin{array}{c}0.043 \\
(0.224)\end{array}$ & $\begin{array}{l}1.195^{* *} \\
(0.581)\end{array}$ & $\begin{array}{c}0.898^{* * *} \\
(0.225)\end{array}$ \\
\hline \multicolumn{8}{|l|}{ B: Drop Compulsory Law Controls } \\
\hline Percent of $0-15$ Treated & $\begin{array}{c}0.073 \\
(0.209) \\
\end{array}$ & $\begin{array}{c}0.027 \\
(0.201) \\
\end{array}$ & $\begin{array}{c}1.073^{* * *} \\
(0.280) \\
\end{array}$ & $\begin{array}{c}0.005 \\
(0.188) \\
\end{array}$ & $\begin{array}{c}0.045 \\
(0.225) \\
\end{array}$ & $\begin{array}{l}1.285^{* *} \\
(0.612)\end{array}$ & $\begin{array}{c}0.840^{* * *} \\
(0.202)\end{array}$ \\
\hline \multicolumn{8}{|l|}{ C: Control for Progressive Laws } \\
\hline Percent of $0-15$ Treated & $\begin{array}{c}0.042 \\
(0.207) \\
\end{array}$ & $\begin{array}{c}0.007 \\
(0.201) \\
\end{array}$ & $\begin{array}{c}1.218^{* * *} \\
(0.324) \\
\end{array}$ & $\begin{array}{c}-0.012 \\
(0.189) \\
\end{array}$ & $\begin{array}{c}0.022 \\
(0.224) \\
\end{array}$ & $\begin{array}{l}1.282^{*} \\
(0.641)\end{array}$ & $\begin{array}{c}1.107^{* * *} \\
(0.224) \\
\end{array}$ \\
\hline Observations & 1555475 & 1393855 & 157028 & 688363 & 705492 & 74351 & 82677 \\
\hline
\end{tabular}

Notes: This table contains results obtained when the dependent variable is years of education and the main independent variable is suffrage exposure, which is defined as the share of time between birth and age 15 that an individual was exposed to a suffrage law in his state of birth. Each panel and column presents estimates from separate regressions. Panel A includes a trend interacted with the pre-treatment education level (defined for a state $\mathrm{x}$ gender $\mathrm{x}$ race cell) as additional controls. Panel B presents estimates dropping compulsory education law controls. Panel C shows results after controlling for other progressive law, including the number of years an individual was exposed to mother's pension laws and prohibition laws between age 0 and 15. All regressions include controls for demographics and state-level characteristics, birth state and birth year fixed effects, birth state linear time trends, as well as region-by-birth year and census year-by-birth year fixed effects. Estimates are weighted using Census sample weights, and standard errors are clustered on the state of birth. The sample consists of individuals born between 1880 and 1930, and that are at least 20 years old at the time of observation. We exclude states that passed suffrage prior to 1900. Source: $1940-1960$ decennial censuses. ${ }^{*} \mathrm{p}<0.10,{ }^{* *} \mathrm{p}<0.05,{ }^{* * *} \mathrm{p}<0.01$. 
Figure A.1: Average Educational Attainment Across Cohorts and Regions

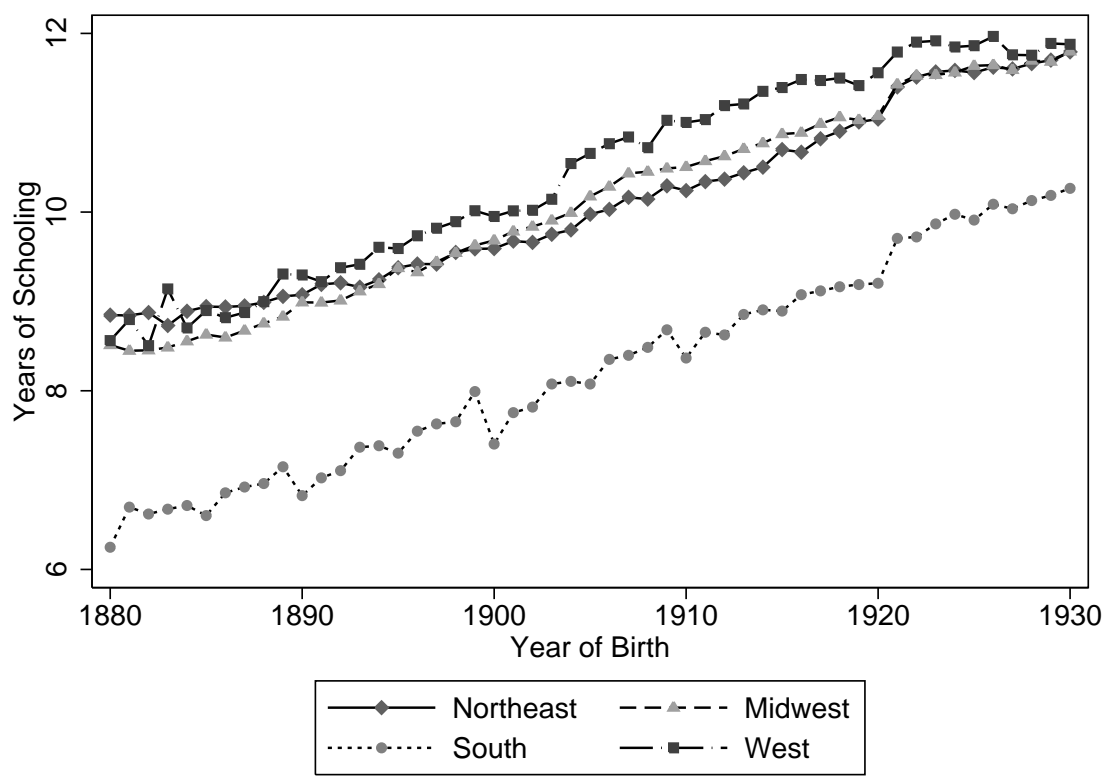

Notes: This figure plots the (weighted) average number of years of completed schooling for U.S. born residents by birth cohort and region. The sample consists of individuals born between 1880 and 1930, and that are at least 20 years old at the time of observation. We exclude states that passed suffrage prior to 1900. Source: 1940-1960 decennial censuses. 
Figure A.2: Subgroup Averages of Pre-Treatment Disadvantage and the Estimated Effects of Suffrage on Years of Education
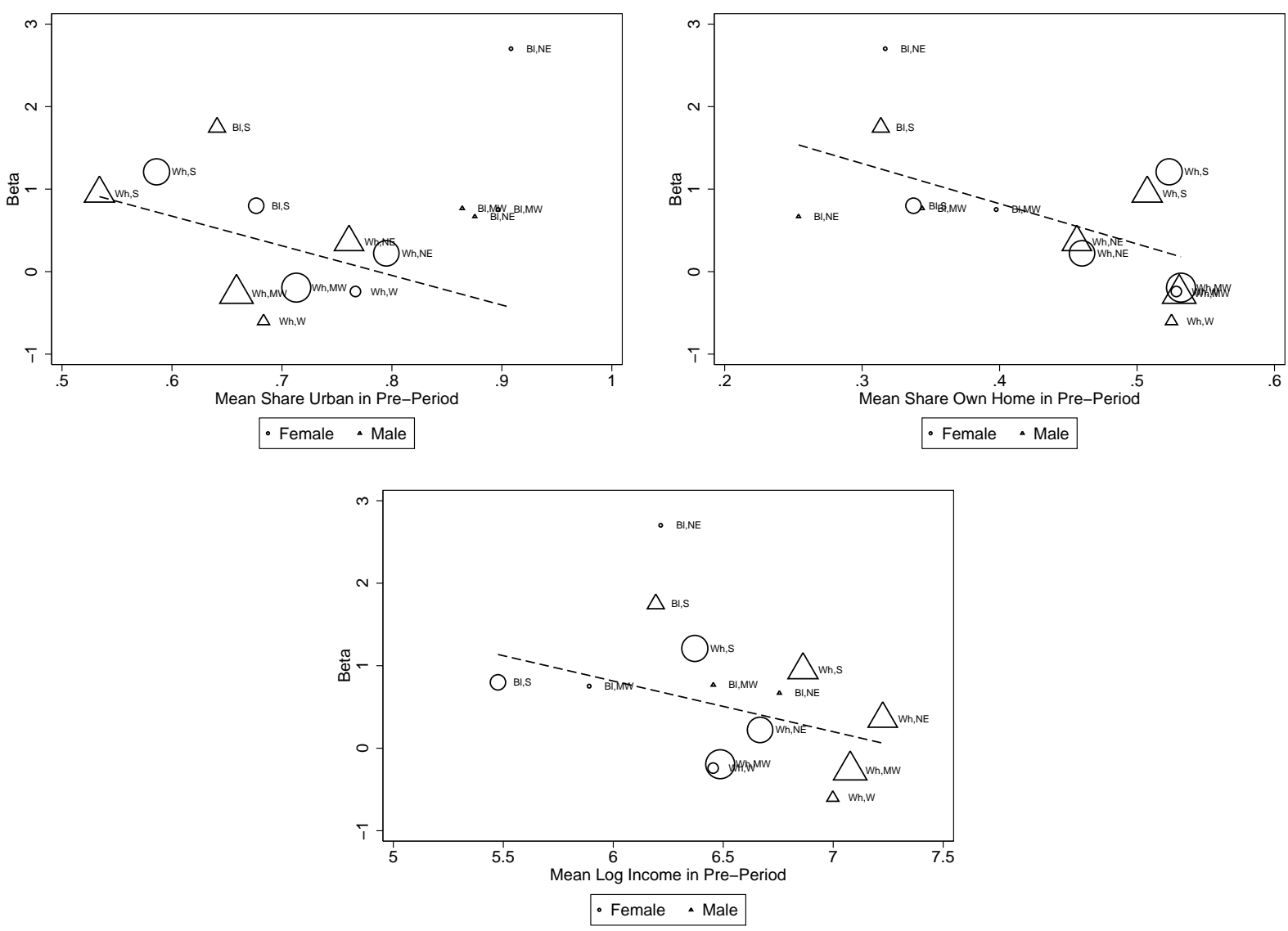

Notes: To create these figures, we first estimate specifications that analyze the effect of suffrage exposure on educational attainment separately for demographic groups defined according to region of birth, race and gender. We then plot the estimated coefficients along with the three different average pre-treatment measure of disadvantage for each demographic group. Regions are abbreviated as follows: "S" for South, "W" for West, "MW" for Midwest, and "NE" for Northeast, and race is abbreviated as: "Bl" for black and "Wh" for white. We do not show blacks in the West due to their small sample size, but an equivalent figure that includes all groups is available on request. All regressions include controls for demographics and state-level characteristics, birth state and birth year fixed effects, birth state linear time trends, as well as region-by-birth year and census year-by-birth year fixed effects. Estimates are weighted using Census sample weights, and standard errors are clustered on the state of birth. The sample consists of individuals born between 1880 and 1930 , and that are at least 20 years old at the time of observation. We exclude states that passed suffrage prior to 1900. Source: 1940-1960 decennial censuses. 
Figure A.3: Effect of Suffrage at Each Age of First Exposure on Years of Education, By Race and South/Non-South

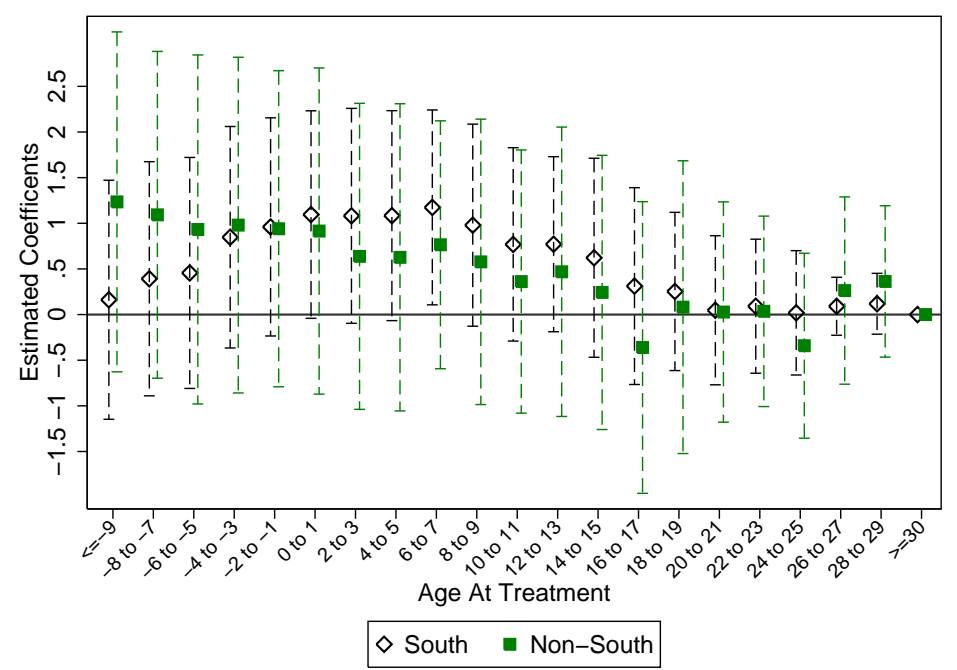

(a) Blacks

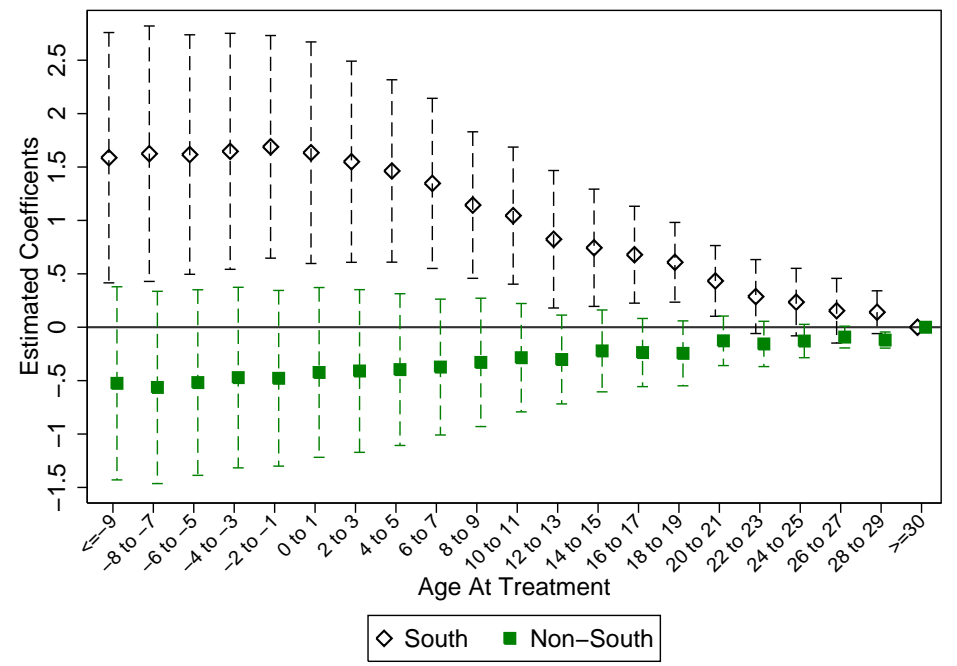

(b) Whites

Notes: This figure plots the estimated coefficients (and 95\% confidence intervals) obtained from event study specifications that analyze the effect of suffrage at each age of first exposure on educational attainment and includes an interaction between the age at treatment dummies and whether the state of birth is in the South or Non-South, estimated separately for whites and blacks. All specifications include controls for demographics and state-level characteristics, birth state and birth year fixed effects, birth state linear time trends, as well as region-by-birth year and census year-by-birth year fixed effects. Age at treatment $\geq 30$ is the omitted category so estimates are relative to that point. Estimates are weighted using Census sample weights, and standard errors are clustered on the state of birth. The sample consists of individuals born between 1880 and 1930, and that are at least 20 years old at the time of observation. We exclude states that passed suffrage prior to 1900. Source: 1940-1960 decennial censuses. 
Figure A.4: Effect of Suffrage at Each Age of First Exposure on Years of Education, Mandatory vs Not Mandatory States

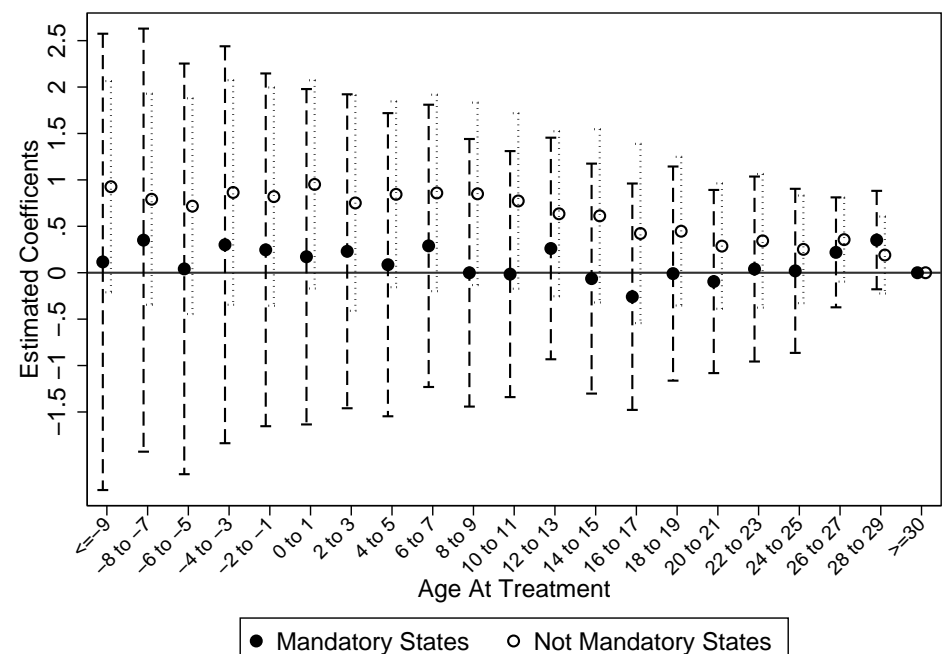

(a) Blacks

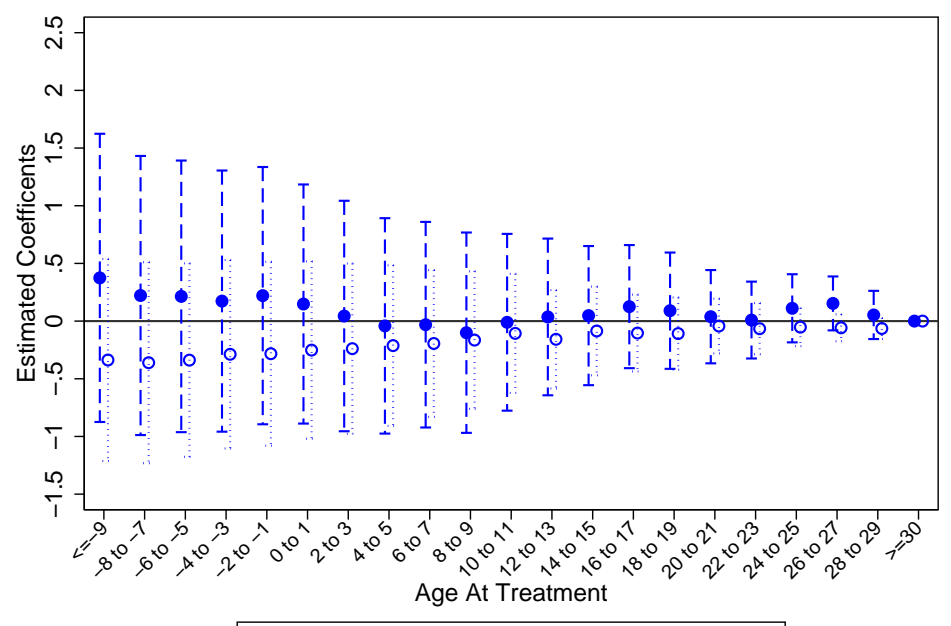

- Mandatory States o Not Mandatory States

(b) Whites

Note: This figure plots the estimated coefficients (and 95\% confidence intervals) obtained from event study specifications that analyze differential effects of suffrage across mandatory and voluntary states at each age of first exposure on educational attainment, separately for whites and blacks. "Mandatory states" are the state that did not pass suffrage prior to the Nineteenth Amendment nor voluntarily ratified it; all others adopted the laws voluntarily. All specifications include controls for demographics and state-level characteristics, birth state and birth year fixed effects, birth state linear time trends, as well as region-by-birth year and census year-by-birth year fixed effects. Estimates are weighted using Census sample weights, and standard errors are clustered on the state of birth. The sample consists of individuals born between 1880 and 1930, and that are at least 20 years old at the time of observation. We exclude states that passed suffrage prior to 1900. Source: 1940-1960 decennial censuses. 


\section{A.1 Discussion of Varying Effects By Age of Treatment}

Here, we begin to probe the potential channels which may have generated the pattern of increasing coefficients with decreasing age of exposure seen in Figure 5. We posit two explanations. The first is a model of child investments which includes complementarities between early investments and later investments (see, e.g. Heckman (2007), Cunha and Heckman (2007)). This theory is re-enforced by recent empirical work on childhood investments, which shows that interventions may be more effective when introduced at early ages because they occur at a critical stage of development during the programming of the body (Hoynes et al., 2016). Under this explanation, children exposed at younger ages experience larger effects because the marginal return to investment is higher. For example, they might experience health improvements at a young age, which lead to improved learning during school. The second explanation is a simple accumulation effect. Children that are treated at younger ages have more time to experience higher quality schooling and sanitation, and therefore remain in school longer.

One way to distinguish between these effects is by investigating whether the effects of suffrage are in fact higher during the earliest ages, as the former theory would suggest. In Table A.11 we quantify the slope of the event study for first exposure at three age ranges; 0-5, 6-10, and 11-15. To do so, we run a regression of years of education on a spline in the number of years an individual was treated between age $0-15$. In this way, the coefficients we estimate represent the marginal effect of an additional year of treatment within each of the ranges, which we denote as $\beta_{05}, \beta_{610}$ and $\beta_{1115}$. Recall that these effects are cumulative, such that an individual treated at age 5 would receive the benefit of $5^{*} \beta_{1115}+5^{*} \beta_{610}+\beta_{05}$, and therefore $\beta_{05}$ should not be interpreted as the entire impact of a year of suffrage for an individual treated between those ages.

Consistent with the Figure 5, Table A.11 reveals that the effect of suffrage is positive and larger during primary school, from age 6 to 10, and that there is little additional effect to exposure prior to age 5 . The shrinking marginal impact of treatment prior to primary school age, a critical stage of development, is suggestive that the second explanation may be more appropriate, although not definitive. The slopes are measured noisily, and we can not reject the equality of the three slopes, as indicated by the p-value at the bottom of the table. 


\section{Table A.11: Effect of Suffrage on Years of Education - Differential Effects Across Different Ages of Exposure}

\begin{tabular}{lccc}
\hline \hline & \multicolumn{3}{c}{} \\
\cline { 2 - 4 } & All & Whites & Blacks \\
\hline Add'l Effect of Treatment from 0-5 & 0.003 & 0.002 & 0.023 \\
& $(0.011)$ & $(0.010)$ & $(0.019)$ \\
Add'l Effect of Treatment between 6-10 & 0.005 & -0.001 & $0.107^{* * *}$ \\
& $(0.019)$ & $(0.018)$ & $(0.037)$ \\
Effect of Treatment between 11-15 & 0.006 & 0.005 & $0.080^{* * *}$ \\
& $(0.012)$ & $(0.012)$ & $(0.029)$ \\
\hline Mean Education & 9.634 & 9.958 & 6.759 \\
P-Value for Test of Equality & 0.948 & 0.788 & 0.212 \\
R-Squared & 0.197 & 0.126 & 0.219 \\
Observations & 1555475 & 1393855 & 157028 \\
\hline \hline
\end{tabular}

Notes: This table contains results obtained when the dependent variable is years of education and the main independent variables are a spline in the number of years an individual is treated between the ages of 0 and 15. Therefore the coefficient for "Treated between X-Y" is the additional impact of one year of treatment during that age range; the text described an example for calculating the total effect of exposure to suffrage. All regressions include controls for demographics and state-level characteristics, birth state and birth year fixed effects, birth state linear time trends, as well as region-by-birth year and census year-by-birth year fixed effects. Estimates are weighted using Census sample weights, and standard errors are clustered on the state of birth. The sample consists of individuals born between 1880 and 1930, and that are at least 20 years old at the time of observation. We exclude states that passed suffrage prior to 1900. Source: $1940-1960$ decennial censuses. ${ }^{*} \mathrm{p}<0.10,{ }^{* *} \mathrm{p}<0.05$, *** $\mathrm{p}<0.01$. 


\section{B Online Appendix}

Figure OA.1: Progressive Era Events over Time

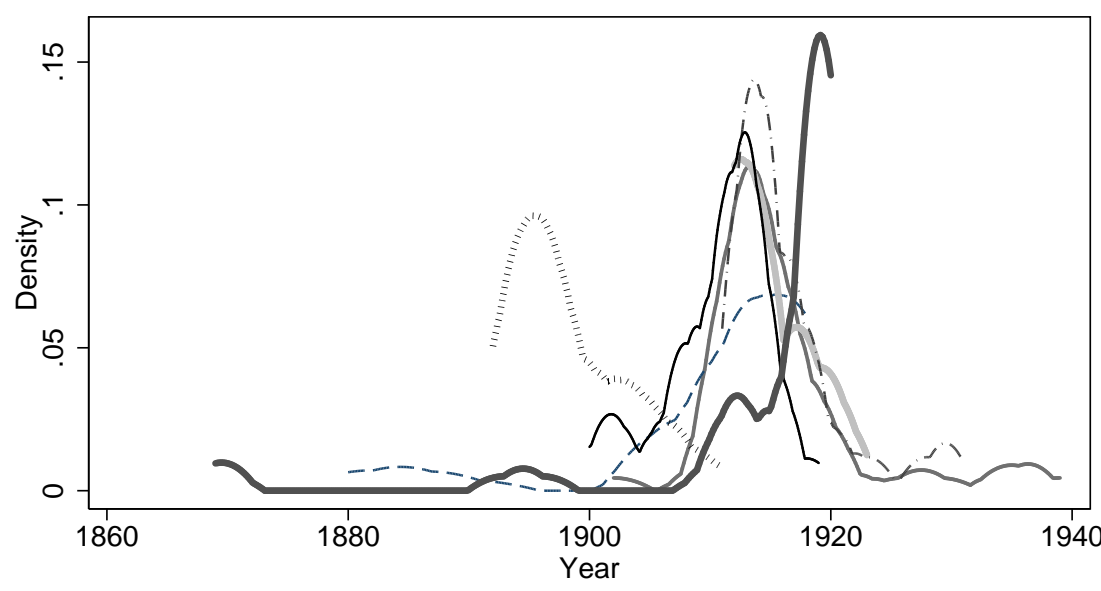

\begin{tabular}{|c|c|c|}
\hline- & $\begin{array}{l}\text { State Workers' Compensation Law } \\
\text { Women's Minimum Wage Law }\end{array}$ & $\begin{array}{l}---- \text { State Prohibition } \\
-\ldots-\cdots \text { State Mother's Pension Law }\end{array}$ \\
\hline 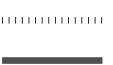 & $\begin{array}{l}\text { GFWC Chapter Established } \\
\text { Women's Suffrage }\end{array}$ & Women's Maximum Hour L \\
\hline
\end{tabular}

Sources: Suffrage laws are from Lott and Kenny (1999) and Miller (2008). Data on mothers pension laws, state General Federation of Womens Clubs chapter establishment, womens maximum hour laws, womens minimum wage laws from Skocpol (1992); workers' compensation law dates from Kantor and Fishback (1996); and state prohibition laws from Depew et al. (2013). 


\section{Table OA.1: Correlation between Timing of Suffrage}

and Progressive Era Laws

\begin{tabular}{lc}
\hline \hline Year of Workers' Compensation Law & -0.145 \\
& $(0.102)$
\end{tabular}

Year of Prohibition

Year of Women's Minimum Wage Law

Year of State Mother's Pension Law

Year of State General Federation of Women's Clubs Chapter
0.382

$(0.488)$
0.389

$(0.282)$
0.696

$(0.417)$

Year of Women's Maximum Hour Law

$(0.391)$

Observations 47 29 15 46 48

40

Notes: This table contains results obtained when the dependent variable is the year of suffrage approved in each state and the main independent variable is the year of the listed Progressive era law. All regressions include region fixed effects. Sources: Suffrage laws are from Lott and Kenny (1999) and Miller (2008). Data on mothers pension laws, state General Federation of Womens Clubs chapter establishment, womens maximum hour laws, womens minimum wage laws from Skocpol (1992); workers' compensation law dates from Kantor and Fishback (1996); and state prohibition laws from Depew et al. (2013).

Table OA.2: Correlation between Suffrage and Compulsory Schooling Laws

\begin{tabular}{lcc}
\hline \hline & Comp. Attendance & Child Labor \\
\hline Post-Suffrage Law & -0.532 & 0.408 \\
& $(0.476)$ & $(0.426)$ \\
\hline Observations & 1440 & 1440 \\
\hline \hline
\end{tabular}

Notes: This table contains results obtained when the dependent variable is the parameter of a compulsory schooling or child labor law and the main independent variable is an indicator for whether suffrage was passed in the state. All regressions include state fixed effects, state trends, and region by year fixed effects. Sources: Data used in Goldin and Katz (2003) obtained from the website of Claudia Goldin. * $\mathrm{p}<0.10, * * \mathrm{p}<0.05, * * * \mathrm{p}<0.01$.

Table OA.3: Correlation between Suffrage and Elements of Compulsory Schooling Laws

\begin{tabular}{lcccc}
\hline \hline & Age Leave Sch. & Age Work & Min Sch. to Work & Min Sch. to Drop \\
\hline Post-Suffrage Law & -0.191 & 0.438 & -0.334 & 7.133 \\
& $(0.397)$ & $(0.807)$ & $(0.533)$ & $(4.772)$ \\
\hline Observations & 1440 & 1440 & 1424 & 1434 \\
\hline \hline
\end{tabular}

Notes: This table contains results obtained when the dependent variable is the parameter of a compulsory schooling or child labor law and the main independent variable is an indicator for whether suffrage was passed in the state. All regressions include state fixed effects, state trends, and region by year fixed effects. Sources: Data used in Goldin and Katz (2003) obtained from the website of Claudia Goldin. ${ }^{*} \mathrm{p}<0.10,{ }^{* *} \mathrm{p}<0.05,{ }^{* * *}$ $\mathrm{p}<0.01$. 
Table OA.4: Effect of Suffrage on Years of Education Keep Early States

\begin{tabular}{|c|c|c|c|c|c|c|c|}
\hline & \multirow[b]{2}{*}{ All } & \multirow[b]{2}{*}{ Whites } & \multirow[b]{2}{*}{ Blacks } & \multicolumn{2}{|c|}{ Whites } & \multicolumn{2}{|c|}{ Blacks } \\
\hline & & & & Males & Females & Males & Females \\
\hline Percent of $0-15$ Treated & $\begin{array}{c}0.133 \\
(0.185)\end{array}$ & $\begin{array}{c}0.083 \\
(0.176)\end{array}$ & $\begin{array}{c}1.142^{* * *} \\
(0.270)\end{array}$ & $\begin{array}{c}0.082 \\
(0.166)\end{array}$ & $\begin{array}{c}0.081 \\
(0.198)\end{array}$ & $\begin{array}{l}1.418^{* *} \\
(0.594)\end{array}$ & $\begin{array}{c}0.893^{* * *} \\
(0.213)\end{array}$ \\
\hline Mean Education & 9.657 & 9.978 & 6.762 & 9.862 & 10.091 & 6.353 & 7.129 \\
\hline R-Squared & 0.198 & 0.127 & 0.219 & 0.138 & 0.118 & 0.213 & 0.216 \\
\hline Observations & 1581878 & 1419943 & 157155 & 701079 & 718864 & 74410 & 82745 \\
\hline
\end{tabular}

Notes: The sample includes all states, including those that passed suffrage prior to 1900 . Suff Share 0-15 is defined as the share of time between birth and age 15 that suffrage law passed in an individual's state of birth. All regressions include controls for demographics and state-level characteristics, birth state and birth year fixed effects, birth state linear time trends, as well as region-by-birth year and census year-by-birth year fixed effects. Estimates are weighted using Census sample weights, and standard errors are clustered on the state of birth. The sample consists of individuals born between 1880 and 1930, and that are at least 20 years old at the time of observation. Source: 1940-1960 decennial censuses. ${ }^{*} \mathrm{p}<0.10,{ }^{* *} \mathrm{p}<0.05,{ }^{* * *} \mathrm{p}<0.01$.

Table OA.5: Effect of Suffrage on Years of Education Individuals 25 or Older Only

\begin{tabular}{|c|c|c|c|c|c|c|c|}
\hline & \multirow[b]{2}{*}{ All } & \multirow[b]{2}{*}{ Whites } & \multirow[b]{2}{*}{ Blacks } & \multicolumn{2}{|c|}{ Whites } & \multicolumn{2}{|c|}{ Blacks } \\
\hline & & & & Males & Females & Males & Females \\
\hline \multirow{2}{*}{ Percent of $0-15$ Treated } & 0.096 & 0.043 & $1.207^{* * *}$ & 0.024 & 0.056 & $1.449^{* *}$ & $0.941^{* * *}$ \\
\hline & $(0.201)$ & $(0.192)$ & $(0.270)$ & $(0.182)$ & $(0.214)$ & $(0.635)$ & $(0.218)$ \\
\hline Mean Education & 9.569 & 9.892 & 6.699 & 9.776 & 10.005 & 6.306 & 7.054 \\
\hline R-Squared & 0.195 & 0.125 & 0.220 & 0.136 & 0.115 & 0.214 & 0.218 \\
\hline Observations & 1424162 & 1276966 & 143098 & 629908 & 647058 & 67855 & 75243 \\
\hline
\end{tabular}

Notes: The sample excludes states that passed suffrage prior to 1900, and is composed of individuals age $\geq 25$. Suff Share 0-15 is defined as the share of time between birth and age 15 that suffrage law passed in an individual's state of birth. All regressions include controls for demographics and state-level characteristics, birth state and birth year fixed effects, birth state linear time trends, as well as region-by-birth year and census year-by-birth year fixed effects. Estimates are weighted using Census sample weights, and standard errors are clustered on the state of birth. Source: $1940-1960$ decennial censuses. ${ }^{*} \mathrm{p}<0.10,{ }^{* *} \mathrm{p}<0.05,{ }^{* * *} \mathrm{p}<0.01$. 
Table OA.6: Effect of Suffrage on Years of Education Insensitivity of Results to the Addition of Controls

\begin{tabular}{|c|c|c|c|c|c|c|}
\hline & $(1)$ & $(2)$ & $(3)$ & $(4)$ & $(5)$ & $(6)$ \\
\hline \multicolumn{7}{|l|}{ A: All } \\
\hline Suff Share 0-15 & $\begin{array}{c}0.486^{* *} \\
(0.220)\end{array}$ & $\begin{array}{c}0.470^{*} \\
(0.236)\end{array}$ & $\begin{array}{c}0.505^{* *} \\
(0.189)\end{array}$ & $\begin{array}{l}0.499^{* *} \\
(0.199)\end{array}$ & $\begin{array}{c}0.495^{* *} \\
(0.198)\end{array}$ & $\begin{array}{c}0.072 \\
(0.217)\end{array}$ \\
\hline Mean Education & 9.634 & 9.634 & 9.634 & 9.634 & 9.634 & 9.634 \\
\hline Observations & 1555475 & 1555475 & 1555475 & 1555475 & 1555475 & 1555475 \\
\hline \multicolumn{7}{|l|}{ B: Whites } \\
\hline Suff Share 0-15 & $\begin{array}{c}0.430^{*} \\
(0.225)\end{array}$ & $\begin{array}{c}0.377 \\
(0.241)\end{array}$ & $\begin{array}{c}0.428^{* *} \\
(0.179)\end{array}$ & $\begin{array}{l}0.426^{* *} \\
(0.184)\end{array}$ & $\begin{array}{c}0.424^{* *} \\
(0.184)\end{array}$ & $\begin{array}{c}0.027 \\
(0.204)\end{array}$ \\
\hline Mean Education & 9.958 & 9.958 & 9.958 & 9.958 & 9.958 & 9.958 \\
\hline Observations & 1393855 & 1393855 & 1393855 & 1393855 & 1393855 & 1393855 \\
\hline \multicolumn{7}{|l|}{ C: Blacks } \\
\hline Suff Share 0-15 & $\begin{array}{c}1.686^{* * *} \\
(0.363) \\
\end{array}$ & $\begin{array}{c}1.621^{* * *} \\
(0.301) \\
\end{array}$ & $\begin{array}{c}1.455^{* * *} \\
(0.256) \\
\end{array}$ & $\begin{array}{c}1.442^{* * *} \\
(0.231) \\
\end{array}$ & $\begin{array}{c}1.413^{* * *} \\
(0.240) \\
\end{array}$ & $\begin{array}{c}1.067^{* * *} \\
(0.251) \\
\end{array}$ \\
\hline Mean Education & 6.759 & 6.759 & 6.759 & 6.759 & 6.759 & 6.759 \\
\hline Observations & 157028 & 157028 & 157028 & 157028 & 157028 & 157028 \\
\hline BSt,BY FE & Yes & Yes & Yes & Yes & Yes & Yes \\
\hline BSt Trends & & Yes & Yes & Yes & Yes & Yes \\
\hline State Controls & & & Yes & Yes & Yes & Yes \\
\hline Compulsory and Rosenwald & & & & Yes & Yes & Yes \\
\hline CYxBY FE & & & & & Yes & Yes \\
\hline RegionxBY FE & & & & & & Yes \\
\hline
\end{tabular}

Notes: This table contains results obtained when the dependent variable is years of education and the main independent variable is suffrage exposure, which is defined as the share of time between birth and age 15 that an individual was exposed to a suffrage law in his state of birth. All regressions include controls for demographics and state-level characteristics, birth state and birth year fixed effects, birth state linear time trends, as well as region-by-birth year and census year-by-birth year fixed effects. Estimates are weighted using Census sample weights, and standard errors are clustered on the state of birth. The sample consists of individuals born between 1880 and 1930, and that are at least 20 years old at the time of observation. We exclude states that passed suffrage prior to 1900 . Source: $1940-1960$ decennial censuses. ${ }^{*} \mathrm{p}<0.10$, ** $\mathrm{p}<0.05, * * * \mathrm{p}<0.01$. 